\title{
Micheliolide, a new sesquiterpene lactone that inhibits intestinal inflammation and colitis-associated cancer
}

\author{
Emilie Viennois ${ }^{1,2}$, Bo Xiao ${ }^{1}$, Saravanan Ayyadurai ${ }^{1}$, Lixin Wang ${ }^{1,2}$, Peng G Wang ${ }^{3,4}$, Quan Zhang ${ }^{4}$, Yue Chen ${ }^{4}$ and \\ Didier Merlin ${ }^{1,2}$
}

Inflammatory bowel diseases (IBD) are chronic inflammatory conditions of the gastrointestinal (GI) tract associated with an increased risk of colorectal cancer (CRC). Current treatments for both IBD and colitis-associated CRC suffer from numerous side effects. Parthenolide (PTL) is a sesquiterpene lactone with anti-inflammatory activity, and previous studies have demonstrated that PTL is a potent inhibitor of the NF- $\kappa$ B pathway. Micheliolide (MCL), substantially more stable than PTL in vivo, was recently developed, and this study aimed to decipher its suitability as therapeutic tool for IBD and IBDassociated diseases. Similar to PTL, MCL inhibited NF- $\kappa$ B activation and subsequent pro-inflammatory pathways activation in vitro. Pro-drug forms of both compounds inhibited the DSS-induced colitis when administrated intraperitoneally or encapsulated in a polysaccharide gel designed to release drugs in the colon. Interestingly, MCL was found to attenuate carcinogenesis in AOM/DSS-induced CRC, thus providing new candidate for the treatment of inflammatory bowel disease and CRC.

Laboratory Investigation (2014) 94, 950-965; doi:10.1038/labinvest.2014.89; published online 28 July 2014

Inflammatory bowel diseases (IBD) are chronic inflammatory conditions of the gastrointestinal (GI) tract. They affect about 1.4 million people in the United States and around 2.2 million people in Europe. ${ }^{1,2}$ Two major clinical forms of IBD have been extensively studied: Crohn's disease $(\mathrm{CD})$ and ulcerative colitis (UC). In CD, inflammation can occur anywhere in the GI tract but it primarily affects the ileum, whereas in UC, the colonic mucosa is principally involved. ${ }^{3}$ However, both diseases are thought to feature alterations in the immune response to GI microbiota in individuals who are genetically predisposed to IBD, which is characterized by intestinal epithelial barrier disruption and an influx of immune cells. ${ }^{4}$ UC is also associated with an increased risk of colorectal cancer (CRC), and the development of CRC in patients with $\mathrm{UC}$ is one of the best clinically characterized examples of association between inflammation and carcinogenesis. ${ }^{5} \mathrm{CRC}$ is one of the most commonly diagnosed cancers and is the second- and third-leading cause of cancer death in males and females, respectively, in developed countries. ${ }^{6}$ This link between chronic inflammation and CRC development has been extensively studied, but the contributing factors and the underlying mechanisms are largely unknown. ${ }^{7-9}$
Parthenolide (PTL), originally isolated from the shoots of feverfew (Tanacetum parthenium), is one of the major sesquiterpene lactones found in this medicinal plant. PTL has a long history of use around the world for preventing migraine headaches and treating rheumatoid arthritis, actions that are attributable to its anti-inflammatory activity. ${ }^{10}$ Several studies have demonstrated that PTL is a potent inhibitor of nuclear factor-kappaB (NF- $\kappa \mathrm{B}$ ) activation and can inhibit the expression of pro-inflammatory cytokines in cultured cells and experimental animal models. ${ }^{11,12}$ One recent study reported that PTL ameliorates dextran sulfate sodium (DSS)-induced colitis in mice, at least in part, through inhibition of NF- $\kappa \mathrm{B}$ activity and downregulation of inflammatory mediators. ${ }^{13}$ In the context of these interesting NF- $\kappa \mathrm{B}$ inhibitory properties, this compound and its derivatives are promising therapeutic agents for treating different inflammation-linked disorders. It has also recently been reported that PTL may inhibit proliferation and apoptosis, and enhance the action of anticancer drugs in various human cancer cells in vitro, including CRC, hepatoma, cholangiocarcinoma, breast cancer, or pancreatic cancer cells. ${ }^{14-18}$ However, detailed molecular mechanisms of these anticancer effects of

\footnotetext{
${ }^{1}$ Institute for Biomedical Sciences, Center for Inflammation, Immunity and Infection, Center for Diagnostics and Therapeutics, Georgia State University, Atlanta, GA, USA; ${ }^{2}$ Veterans Affairs Medical Center, Decatur, GA, USA; ${ }^{3}$ Department of Chemistry, Center for Diagnostics and Therapeutics, Georgia State University, Atlanta, GA, USA and ${ }^{4}$ The State Key Laboratory of Elemento-Organic Chemistry, Nankai University, Tianjin 300071, China Correspondence: Dr E Viennois, PhD, Center for Diagnostics and Therapeutics, Georgia State University, Atlanta, GA 30303, USA. E-mail: eviennois@gsu.edu
} 
PTL are largely unknown. The water-soluble Michael adduct of PTL, dimethylaminoparthenolide (DMAPT), shows improved solubility and bioavailability compared with PTL and has entered clinical trials for cancer therapy. ${ }^{19}$ DMAPT is the pro-drug form of PTL, which is released from DMAPT in the plasma at $\mathrm{pH} 7.4^{20}$ It has been reported that DMAPT promotes cell death by generating reactive oxygen species as well as by inhibiting the NF- $\kappa \mathrm{B}$ signaling pathway, ${ }^{21}$ and displays growth-inhibitory properties against tobaccoassociated cancer of the lung and bladder. ${ }^{22}$

Importantly, PTL is unstable in both acidic and basic conditions, ${ }^{23}$ leading us to the development of the structurally related compound, micheliolide (MCL). MCL is seven times more stable than PTL in vitro, suggesting that it would be more stable in vivo. ${ }^{20} \mathrm{MCL}$ is a guaianolide sesquiterpene lactone isolated from Michelia compressa and Michelia champaca and can also be in vitro synthesized from PTL. ${ }^{24}$ The Michael adduct of MCL, dimethylaminomicheliolide (DMAMCL), exhibits remarkable therapeutic efficacy in murine models of acute myelogenous leukemia. ${ }^{20}$ In plasma, DMAMCL and DMAPT are transformed into MCL and PTL, respectively, but DMAPT is rapidly converted to PTL, whereas DMAMCL releases MCL slowly but continuously. ${ }^{20}$ Accordingly, the half-life of DMAMCL is much longer, indicating that DMAMCL has more interesting in vivo pharmacokinetic properties than DMAPT as a pro-drug, an advantage that might enhance its therapeutic potential.

To date, MCL and its water-soluble Michael adduct, DMAMCL, have only been reported as inhibitors of acute leukemic cells..$^{25,26}$ The present study aimed to compare the anti-inflammatory and NF- $\kappa \mathrm{B}$ pathway-inhibitory effects of MCL and PTL in vitro and the effect of DMAPT or DMAMCL on DSS-induced colitis. As it is known that chronic colonic inflammation can lead to colitis-associated cancer (CAC), we investigated DMAMCL and DMAPT effects in an azoxymethane $(\mathrm{AOM}) / \mathrm{DSS}$ model of CAC. Taken together, the finding of this study provide experimental evidence that both DMAPT and DMAMCL possess strong anti-inflammatory properties when orally administrated and could be envisaged as therapeutic agents for patients with IBD and CAC. This is especially true for DMAMCL, which has a much longer half-life and greater efficacy against CAC.

\section{MATERIALS AND METHODS}

MCL and DMAMCL Synthesis

PTL and DMAPT were purchased from Accendatech (Tianjin, China).

Synthesis of MCL (Figure 1a): To a solution of p-toluenesulfonic acid $(43.7 \mathrm{~g}, 0.25 \mathrm{~mol})$ in $\mathrm{CH}_{2} \mathrm{Cl}_{2}(15.8 \mathrm{~kg})$ was added dropwise a solution of PTL $(1.75 \mathrm{~kg}, 7.06 \mathrm{~mol})$ in $\mathrm{CH}_{2} \mathrm{Cl}_{2}(3.5 \mathrm{~kg})$ at $20^{\circ} \mathrm{C}$ for $8 \mathrm{~h}$. The resulting reaction mixture was stirred at room temperature for $15 \mathrm{~h}$. The reaction was quenched with $9.1 \% \mathrm{NaHCO}_{3}(550 \mathrm{~g})$. The organic layer was washed with saturated brine $(2 \times 2 \mathrm{~kg})$, decolorized with activated carbon $(100 \mathrm{~g})$, and concentrated a

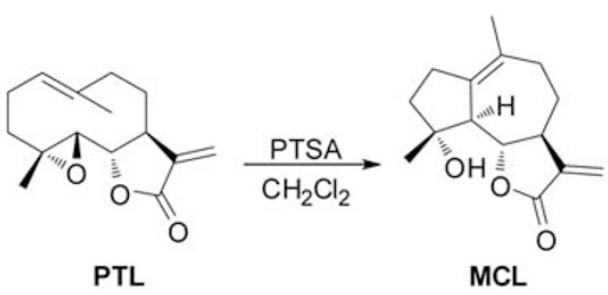

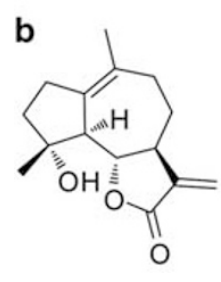

MCL

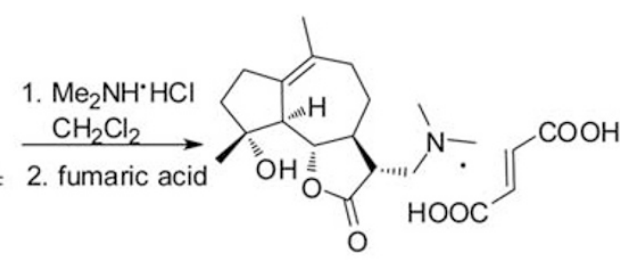

DMAMCL
Figure 1 Synthesis of MCL and DMAMCL. (a) MCL was synthetized from PTL. (b) DMAMCL was synthetized form MCL.

under reduced pressure to give a crude residue, which was recrystallized from acetone to yield a colorless needle, MCL $(1.58 \mathrm{~kg}, 90 \%) .{ }^{1} \mathrm{H}$ NMR $\left(\mathrm{CDCl}_{3}, 400 \mathrm{MHz}\right) \delta 6.20(\mathrm{~d}, J=$ $\left.3.2 \mathrm{~Hz},{ }^{1} \mathrm{H}\right), 5.49\left(\mathrm{~d}, J=3.2 \mathrm{~Hz},{ }^{1} \mathrm{H}\right), 3.81\left(t, J=10.4 \mathrm{~Hz},{ }^{1} \mathrm{H}\right)$, $2.70\left(\mathrm{~d}, J=10.4 \mathrm{~Hz},{ }^{1} \mathrm{H}\right), 2.65-2.62(\mathrm{~m}, 2 \mathrm{H}), 2.40-2.34$ $(\mathrm{m}, 1 \mathrm{H}), 2.07-2.26(\mathrm{~m}, 4 \mathrm{H}), 1.73-1.86(\mathrm{~m}, 2 \mathrm{H}), 1.68(\mathrm{~s}, 3 \mathrm{H})$, $1.36-1.28(\mathrm{~m}, 4 \mathrm{H}) ;{ }^{13} \mathrm{C}$ NMR $\left(\mathrm{CDCl}_{3}, 100 \mathrm{MHz}\right) \delta 169.8$, $138.7,131.7,130.8,119.5,84.1,80.2,58.5,49.5,38.2,34.8$, 30.0, 25.7, 23.9, 23.6.

Synthesis of DMAMCL (Figure 1b): A mixture of $\mathrm{Me}_{2} \mathrm{NH} . \mathrm{HCl}(1.5 \mathrm{~g}, 18 \mathrm{mmol}), \mathrm{K} 2 \mathrm{CO} 3(5.0 \mathrm{~g}, 36 \mathrm{mmol})$, and $\mathrm{CH}_{2} \mathrm{Cl}_{2}(100 \mathrm{ml})$ was stirred at room temperature until $\mathrm{Me}_{2} \mathrm{NH} . \mathrm{HCl}$ was dissolved. The mixture was filtered as soon as possible. The resulting solution was treated with MCL (300 $\mathrm{mg}, 1.2 \mathrm{mmol}$ ) and stirred at room temperature for $3 \mathrm{~h}$. The reaction mixture was concentrated under reduced pressure. The residue was dissolved in $\mathrm{CH}_{2} \mathrm{Cl}_{2}$, and then washed with water. The organic layer was dried with $\mathrm{Na}_{2} \mathrm{SO}_{4}$, concentrated under reduced pressure to give DMAMCL (291 mg, 82\%): ${ }^{1} \mathrm{H} \quad \mathrm{NMR} \quad\left(\mathrm{CDCl}_{3}, 400 \mathrm{MHz}\right) \quad \delta \quad 3.76$ $(t, J=10.0 \mathrm{~Hz}, 1 \mathrm{H}), 2.96(\mathrm{~s}, 1 \mathrm{H}), 2.49-2.67(\mathrm{~m}, 3 \mathrm{H}), 2.28-$ $2.34(\mathrm{~m}, 1 \mathrm{H}), 2.30-2.34(\mathrm{~m}, 2 \mathrm{H}), 2.18(\mathrm{~s}, 6 \mathrm{H}), 2.09$ (br s, $2 \mathrm{H}), \quad 1.96(d, J=11.2 \mathrm{~Hz}, 1 \mathrm{H}) \quad 1.67-1.73(\mathrm{~m}, 2 \mathrm{H}), 1.60$ (s, 3H), 1.22 (br s, $3 \mathrm{H}), 1.18$ (br s, $2 \mathrm{H}) ;{ }^{13} \mathrm{C} \mathrm{NMR}\left(\mathrm{CDCl}_{3}\right.$, $300 \mathrm{MHz}) \delta 177.0,131.8,131.3,84.0,80.2,58.3,58.1,50.9$, 46.0, 44.6,38.4, 35.3, 30.0, 27.2, 23.7, 22.8 .

A mixture of DMAMCL $(291 \mathrm{mg})$, fumaric acid $(114 \mathrm{mg}$, $0.98 \mathrm{mmol})$ and EtOAc $(8 \mathrm{ml})$ was refluxed for $5 \mathrm{~h}$. The resulting mixture was filtrated to give DMAMCL $(369 \mathrm{mg}$, 91\%) as an amorphous solid. ${ }^{1} \mathrm{H}$ NMR (dimethyl sulfoxide (DMSO), $500 \mathrm{MHz}) \delta 6.58(\mathrm{~s}, 2 \mathrm{H}), 3.80\left(t, J=10.3 \mathrm{~Hz},{ }^{1} \mathrm{H}\right)$, $2.64(\mathrm{~s}, 3 \mathrm{H}), 2.49-2.53(\mathrm{~m}, 3 \mathrm{H}), 2.26-2.27(\mathrm{~m}, 1 \mathrm{H}), 2.23$ (s, 6H), 1.96-2.10 (m, 6H), $1.60(\mathrm{~s}, 3 \mathrm{H}), 1.57-1.59(\mathrm{~m}, 2 \mathrm{H})$, $1.23-1.25(\mathrm{~m}, 1 \mathrm{H}), 1.15(\mathrm{~s}, 3 \mathrm{H}) ;{ }^{13} \mathrm{C}$ NMR (DMSO, $125 \mathrm{MHz}) \delta 177.8,167.6(2 \mathrm{C}), 135.2(2 \mathrm{C}), 133.7,131.4,83.4$, 
80.31, 58.0, 57.1, 51.7, 45.2(2C), 43.6, 41.0, 35.3, 30.2, 27.0, $24.2,23.2$.

\section{Cell Culture}

RAW 264.7 cells or Caco-2BBE cells were cultured in order to reach confluence in $75-\mathrm{cm}^{2}$ flasks at $37^{\circ} \mathrm{C}$ in a humidified atmosphere containing $5 \% \mathrm{CO}_{2}$. The culture medium used was DMEM medium (Life Technologies, Grand Island, NY, USA) supplemented with penicillin $(100 \mathrm{U} / \mathrm{ml})$, streptomycin $(100 \mathrm{U} / \mathrm{ml})$, and heat-inactivated fetal bovine serum $(10 \%)$ (Atlanta Biologicals, Lawrenceville, GA, USA). For subsequent experiments, $1.5 \times 10^{5}$ RAW 264.7 cells per well were plated in six-well plates. For enzyme-linked immunosorbent assay (ELISA), the cells were incubated in the presence of $10 \mathrm{ng} / \mathrm{ml}$ of LPS (Sigma, St Louis, MO, USA) for $1 \mathrm{~h}$ and then incubated with 1, 2, 5, or $10 \mu \mathrm{M}$ of either PTL or MCL. After $8 \mathrm{~h}$, the cell supernatants were collected. For RNA analysis, cells were incubated $8 \mathrm{~h}$ with $1,2,5$, or $10 \mu \mathrm{M}$ of PTL or MCL and then $1 \mathrm{~h}$ with $10 \mathrm{ng} / \mathrm{ml}$ of LPS. For western blot analysis, the cells were incubated for $8 \mathrm{~h}$ with $5 \mu \mathrm{M}$ of PTL or MCL and then with $10 \mu \mathrm{g} / \mathrm{ml}$ of LPS for $0,10,20,40$, or $60 \mathrm{~min}$.

\section{Cytotoxicity Test}

To assess toxicity effect of PTL or MCL, a WST-1 assay was performed. RAW 264.7 cells were seeded in 96-wells plate at a density of $6 \times 10^{3}$ cells per well and exposed to $0,1,2,5$, or $10 \mu \mathrm{M}$ of PTL or MCL for $24 \mathrm{~h}$. Triton X-100 (0.1\%, v/v) was used as a positive control of mortality; with the subsequent value established as $0 \%$ of viability. The WST-1 assay measures cleavage of the soluble red tetrazolium salt, WST-1 (4-[3-(4-iodophenyl)-2-(4-nitrophenyl)-2H-5-tetrazolio]-1,3benzene disulfonate), by dehydrogenase present in intact mitochondria, which leads to the formation of dark red formazan crystals. WST-1 proliferation reagent (Roche) was added to RAW 264.7 cells and incubated for $4 \mathrm{~h}$ at $37^{\circ} \mathrm{C}$, with $5 \%$ of $\mathrm{CO}_{2}$. The absorbance was measured at $440 \mathrm{~nm}$.

\section{Cell Transfection and Luciferase Assay}

For transfection experiment, $1.5 \times 10^{5}$ RAW 264.7 cells per well were plated in six-well plates. After $16 \mathrm{~h}$, transient transfection of $2 \mu \mathrm{g} /$ well of the pGL4.32[luc2P/NF- $\kappa \mathrm{B}-\mathrm{RE} /$ Hygro] Vector (Promega, Madison, WI) was performed in OPTI-MEM using Lipofectamin (Life Technologies). After $24 \mathrm{~h}$ transfection, cells were co-treated with LPS $(100 \mathrm{ng} / \mathrm{ml})$ and different concentrations of PTL or MCL $(1,2$, and $5 \mu \mathrm{M})$. After $8 \mathrm{~h}$ of incubation, cells were lysed by $1 \times$ lysis buffer and the luciferase activity was read using Promega assay system (Promega).

\section{Protein Extraction and Western Blot Analysis}

Cells were lysed in radioimmune precipitation assay buffer $(150 \mathrm{mM} \mathrm{NaCl}, 0.5 \%$ sodium deoxycholate, $50 \mathrm{mM}$ Tris- $\mathrm{HCl}$, $\mathrm{pH} 8,0.1 \%$ SDS, $0.1 \%$ Nonidet P-40) supplemented with protease inhibitors (Roche Diagnostics) for $30 \mathrm{~min}$ on ice. Homogenates were centrifuged at $16000 \mathrm{~g}$ for $20 \mathrm{~min}$ at $4{ }^{\circ} \mathrm{C}$.
Total cell lysates were resolved on polyacrylamide gels and transferred to nitrocellulose membranes (Bio-Rad). Membranes were then probed with relevant primary antibodies: anti- $\mathrm{I} \kappa \mathrm{B} \alpha$ (dilution 1:1000; Santa Cruz \# sc-371, Dallas, TX), anti-phospho (Ser32/36)-I $\kappa \mathrm{B} \alpha$ (dilution 1:400; Cell Signaling \# 9246, Danvers, MA), anti-NF- $\kappa$ B-p65 (dilution 1:1000; Cell Signaling \# 8242), anti-phospho (Ser536)-NF-kB-p65 (dilution 1:400; Cell signaling \# 3033), anti-CyclinD1 (dilution 1:250; Santa Cruz \# sc-20044), anti-PCNA (dilution 1:250; Santa Cruz \# sc-56), and the anti- $\beta$-actin (dilution 1:5000; Cell signaling \# 3700). After washes, membranes were incubated with appropriate horseradish peroxidase-conjugated secondary antibodies (Dilution 1:5000, GE Healthcare Biosciences, Pittsburgh, PA, USA), and blots were detected using the Enhanced Chemiluminescence Detection kit (GE Healthcare Biosciences). Densitometry quantifications were performed using the software Quantity One (Bio-Rad).

\section{RNA Extraction and Real-Time RT-PCR}

Total RNA were extracted from RAW 264.7 cells or from colonic tissues using respectively TRIzol (Life Technologies) or RNeasy mini Kit (Qiagen) according to the manufacturer's instructions. Colonic RNA were purified via precipitation with lithium chloride. ${ }^{27}$ Yield and quality of RNA were verified with a Synergy 2 plate reader (BioTek, Winooski, VT, USA). cDNA were generated from the total RNA isolated above using the Maxima first-strand cDNA synthesis kit (Thermo Scientific, Lafayette, CO, USA). mRNA expression were quantified by quantitative real-time reverse transcription-PCR (qRT-PCR) using Maxima SYBR green/ ROX (6-carboxyl-X-rhodamine) quantitative PCR (qPCR) Master Mix (Thermo Scientific) and the following sense and antisense primers: IL-1 $\beta 5^{\prime}$-TCGCTCAGGGTCACAAGAAA- $3^{\prime}$ and $5^{\prime}$-CATCAGAGGCAAGGAGGAAAAC- $3^{\prime}$; tumor necrosis factor $\alpha$ (TNF $\alpha)$ 5'-AGGCTGCCCCGACTACGT- $3^{\prime}$ and $5^{\prime}$-GACTTTCTCCTGGTATGAGATAGCAAA- ${ }^{\prime}$; IL-6 5'-ACA AGTCGGAGGCTTAATTACACAT- $3^{\prime}$ and $5^{\prime}$-TTGCCATTGC ACAACTCTTTTC-3'; TGF- $\beta$ 5'-TGCGCTTGCAGAGATTA AAA- $3^{\prime}$ and $5^{\prime}$-AGACAGCCACTCAGGCGTAT-3'; 36B4 $5^{\prime}$-TCCAGGCTTTGGGCATCA- $3^{\prime}$ and $5^{\prime}$-CTTTATCAGCT GCACATCACTCAGA- $3^{\prime}$. Results were normalized by using 36B4 housekeeping gene.

\section{Epithelium Resistance Measurement by Electric Cell Substrate Impedance Sensing (ECIS)}

For ECIS, cell-attachment assays were performed using ECIS technology (Applied BioPhysics, Troy, NY, USA) ${ }^{28}$ The ECIS model 1600R (Applied BioPhysics) was used for these experiments. Measurement system consists of an 8-well culture plate (ECIS 8W1E plate), the surface of which is seeded with cells. Each well contains a small, active electrode ( $\operatorname{area}=$ $\left.5.1024 \mathrm{~cm}^{2}\right)$ and a large counter electrode (area $=0.15 \mathrm{~cm}^{2}$ ) on the bottom of each well. A lock-in amplifier, with an internal oscillator, relays a signal to switch between the 
different wells. Attachment and spreading of cells on the electrode surface change the impedance in such a way that morphological information about the attached cells can be inferred. Caco2-BBE cells $\left(1 \times 10^{6} / \mathrm{ml}\right)$ were seeded in ECIS 8W1E plates in DMEM (Life Technologies) supplemented with $10 \%(\mathrm{v} / \mathrm{v})$ heat-inactivated fetal bovine serum (Atlanta Biologicals). Once cells reached confluence, the different solutions were added at $0,1,2$, and $5 \mu \mathrm{M}$. DMSO controls in DMEM medium cell cultures were used. Basal resistance measurements were performed at a frequency of $500 \mathrm{~Hz}$ and a voltage of $1 \mathrm{~V}$.

\section{Encapsulation of DMAPT or DMAMCL into Hydrogel}

Chitosan powder was solubilized in acetic acid and then neutralized by addition of $\mathrm{NaOH}(0.1 \mathrm{~mol} / \mathrm{l})$ to give a final concentration of $0.6 \%(\mathrm{wt} / \mathrm{vol})$. Medium viscosity sodium alginate was prepared in $\mathrm{NaCl}(0.15 \mathrm{~mol} / \mathrm{l}) 1.4 \%$ (wt/vol). Alginate solution and chitosan solutions were mixed at a 1:1 ratio for a final concentration of 7 and $3 \mathrm{~g} / \mathrm{l}$, respectively. The polymer suspension was homogenized for $24 \mathrm{~h}$. The molecules DMAPT or DMAMCL were added to obtain a $4 \mathrm{mg} / \mathrm{ml}$ concentration in hydrogel solution and stirred to disperse the molecules throughout the polymer solution. A chelation solution containing $70 \mathrm{mmol} / \mathrm{l}$ of calcium chloride and $30 \mathrm{mmol} / \mathrm{l}$ of sodium sulfate was prepared. The administration and the chelation of the hydrogel were realized using a double gavage method as previously described. ${ }^{29}$

\section{Immunofluorescence Detection of NF- $\boldsymbol{k B}$-p65 Complex}

Raw 264.7 macrophages were seeded in eight-chamber tissue culture glass slide (BD Falcon, Bedford, MA, USA) at a density of $2 \times 10^{4}$ cells/well and incubated overnight. The cells were incubated for $8 \mathrm{~h}$ with $5 \mu \mathrm{M}$ of PTL, MCL, or the DMSO control and then induced by $10 \mu \mathrm{g} / \mathrm{ml}$ of LPS for $30 \mathrm{~min}$. After induction, the cells were fixed in $4 \%$ paraformaldehyde for $10 \mathrm{~min}$ and permeabilized for $20 \mathrm{~min}$ Triton $\mathrm{X}-100(0.1 \%, \mathrm{v} / \mathrm{v})$. After blocking, the cells were incubated with rabbit anti-NF- $\kappa \mathrm{B}-\mathrm{p} 65$ antibody (dilution 1:50; Cell Signaling \# 8242) and with anti-rabbit conjugated with Alexa 488 secondary antibody (dilution 1:50; Life Technologies). Cells were covered with mounting medium containing 4-,6diamidino-2-phenylindole (DAPI) (Vector Laboratories; $\mathrm{H}-1500)$ and cover slipped. Observations and acquisition were performed with a Zeiss LSM 700 confocal microscope with software Zen 2011 version 7.1.

\section{Scanning Electron Microscopy}

A drop of hydrogel was applied to glass coverslips, freezedried and sputter coated with $\mathrm{Au} / \mathrm{Pd}$ using a Denton desktop sputter coater (Moorestown, NJ, USA). LEO 1450VP microscope (New York, NY, USA) was used for analysis.

\section{Mice}

Eight-week old female C57BL/6 mice or FVB/NJ were purchased from Jackson Laboratories. Mice were housed in specific pathogen-free conditions and fed ad libitum. All the experiments involving mice were approved by institutional animal care and use committee (IACUC, Georgia State University Atlanta, GA, USA), permit number A11027, A11025 and A11023.

\section{DSS-Induced Colitis and DMAMCL/DMAPT Treatment}

Wild-type (WT) C57BL/6 mice were pre-treated by IP injection or by double gavage in hydrogel for 5 days, respectively, with $5 \mathrm{mg} / \mathrm{kg}$ or $40 \mathrm{mg} / \mathrm{kg}$ of body weight of DMAMCL or DMAPT, or water administrated as control. Appropriate water control mice were also used for this study. After 5 days, in addition of the DMAMCL and DMAPT, mice were administered DSS (MP Biomedicals, Solon, OH, USA) at $1.5 \%$ in drinking water ad libitum for 7 days (five mice per group). Control mice were given water only. During this period, mice were weighed every day. After 7 days, mice were bled via retro-orbital plexus and hemolysis-free serum was collected by centrifugation using serum separator tubes (BD Biosciences, Franklin Lakes, NJ, USA). Mice were killed by $\mathrm{CO}_{2}$ euthanasia. Spleen and colon length were measured. A small piece $(50 \mathrm{mg}$ ) of distal colon was taken for MPO and RNAs analysis, and the remaining of the colon was used for colonic culture supernatant and histopathological analysis.

\section{Colitis-Associated Cancer Induction and DMAMCL/ DMAPT Treatment}

WT FVB/NJ mice were pre-treated during 5 days with $10 \mathrm{mg} / \mathrm{kg}$ of body weight of DMAMCL or DMAPT or water by IP injection. After 5 days, in addition to the DMAMCL and DMAPT, CAC was induced as previously described, ${ }^{30}$ with some modifications. Mice were IP injected with AOM $(10 \mathrm{mg} / \mathrm{kg}$ body weight $)$ and maintained on regular diet and water for 5 days. Mice were then subjected to two cycles of DSS treatment, in which each cycle consisted of $2.5 \%$ DSS for 7 days followed by a 14-day recovery period with regular water. Colonic tumors were counted and measured using a dissecting microscope.

\section{H\&E Staining of Colonic Tissue and Histopathologic Analysis}

Mouse colons were fixed in 10\%-buffered formalin for $24 \mathrm{~h}$ at room temperature and then embedded in paraffin. Tissues were sectioned at $5-\mu \mathrm{m}$ thickness and stained with hematoxylin \& eosin (H\&E) using standard protocols. Images were acquired using a Zeiss Axioskop 2 plus microscope (Carl Zeiss MicroImaging) equipped with an AxioCam MRc5 CCD camera (Carl Zeiss). For the colitis model, each colon was assigned four scores based on the degree of epithelial damage and inflammatory infiltrate in the mucosa, submucosa, and muscularis/serosa, as previously described. ${ }^{31} \mathrm{~A}$ slight modification was made to this scoring system; each of the four scores was multiplied by one if the change was focal, two if it was patchy, and three if it was diffuse, as previously 
described. ${ }^{32}$ The four individual scores per colon were added, resulting in a total scoring range of $0-36$ per mouse. The scores for each of five mice per treatment group were averaged.

\section{Colonic Myeloperoxidase (MPO) Assay}

Neutrophil influx in colon was analyzed as marker of inflammation by assaying the enzymatic activity of MPO, a neutrophils marker. Briefly, tissue $(50 \mathrm{mg} / \mathrm{ml})$ was thoroughly washed in PBS and homogenized in 0.5\% hexadecyltrimethylammonium bromide (Sigma) in $50 \mathrm{mM}$ PBS, $(\mathrm{pH}$ 6.0), freeze-thawed three times, sonicated, and centrifuged. MPO was assayed in the clear supernatant by adding $1 \mathrm{mg} / \mathrm{ml}$ of dianisidine dihydrochloride (Sigma) and $0.0005 \% \mathrm{H}_{2} \mathrm{O}_{2}$ and the change in optical density measured at $450 \mathrm{~nm}$. Human neutrophil MPO (Sigma) was used as standard. One unit of MPO activity was defined as the amount that degraded $1 \mathrm{mmol}$ peroxidase per minute.

\section{ELISA}

TNF $\alpha$ levels were quantified in colonic culture supernatant using TNF $\alpha$ RSG ELISA kit (eBiosciences, San Diego, CA, USA) according to manufacturer's instructions. IL- $1 \beta$ and IL6 were, respectively, quantified from colonic supernatant and serum using Duoset cytokine ELISA kits (R\&D Systems, Minneapolis, MN, USA).

\section{Statistics Analysis}

Statistical analysis for significance $(P<0.05)$ was determined using ANOVA test followed by a Bonferroni post-test (GraphPad Prism). Differences were noted as significant. ${ }^{\star} P<0.05$.

\section{RESULTS}

\section{MCL is not Cytotoxic}

In order to assess the cytotoxicity of MCL in comparison with PTL, we tested these compounds at different concentrations $(0,1,2,5$, and $10 \mu \mathrm{M})$ with the RAW 264.7 macrophage-like cell line using the cell proliferation reagent WST-1 (Figure 2a and b). The value obtained with $0.1 \%$ Triton X-100 (cytotoxicity-positive control) was used to establish $0 \%$ viability. After $8 \mathrm{~h}$ of treatment, cell viability of RAW 264.7 was not altered by any concentration of PTL. Although the cell viability was not at $100 \%$ after MCL treatment, MCL does not present any significant cell toxicity on RAW 264.7 cells. ECIS was then used as another method for testing real-time toxicity. As shown in Figure $2 \mathrm{c}$ and d, Caco2-BBE cells were attached to the electrode surface and
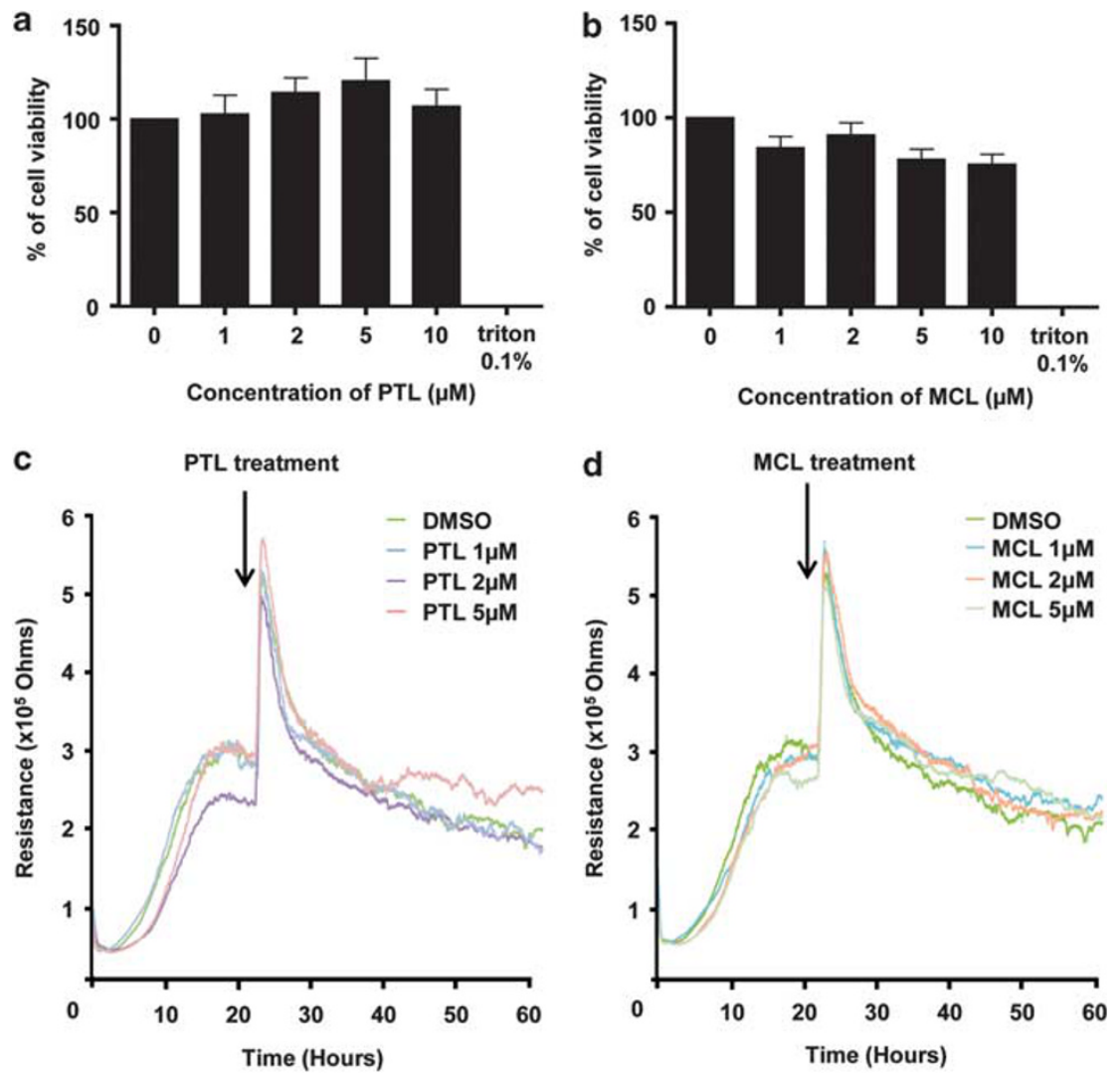

Figure 2 PTL and MCL do not induce cytotoxicity in macrophages or epithelial cells. The WST-1 reagent was used to assess the cytotoxicity of different concentrations $(0,1,2,5$, and $20 \mu \mathrm{M}$ ) of PTL (a) and MCL (b) in RAW 264.7 cells after a 24-h exposure. (c, d) ECIS was used to determine cell viability after a long exposure $(60 \mathrm{~h})$ of Caco2-BBE cell monolayers to 1 , 2, or $5 \mu \mathrm{M}$ PTL (c) or MCL (d). 
allowed to form a confluent monolayer, which reached a resistance of about $30000 \Omega$ after $20 \mathrm{~h}$. Different concentrations of PTL and MCL $(0,1,2,5 \mu \mathrm{M})$ were added to the confluent Caco2-BBE monolayer leading to a transient increase in resistance. Thereafter, the resistance of Caco2-BBE monolayers decreased sharply, returning to $\sim 30000 \Omega$ after $30 \mathrm{~h}$. Under all conditions, the resistance of the cell monolayer gradually decreased. However, neither PTL (Figure 2c) nor MCL (Figure 2d) at any concentration altered the resistance of the Caco2-BBE cell monolayer compared with DMSO controls. Taken together with the results of WST-1 cell viability assays, these results confirm that MCL, just like PTL, is not toxic in vitro.

\section{Displays the Same Anti-Inflammatory Effect as PTL in RAW 264.7 Macrophages}

We then activated pro-inflammatory pathways using LPS, which is recognized by Toll-like receptor 4 , and analyzed proinflammatory gene expression by quantitative real-time reverse transcription-polymerase chain reaction (qRT-PCR). For this purpose, RAW 264.7 cells were stimulated with LPS at a concentration of $10 \mathrm{ng} / \mathrm{ml}$, and then co-stimulated with different concentrations of PTL or MCL. As shown in Figure $3 a$ and $b$, LPS induced the synthesis and secretion of the pro-inflammatory cytokines interleukin (IL)- 6 and IL-1 $\beta$ by RAW 264.7. Interestingly, co-treatment with MCL, like PTL, inhibited the synthesis of IL- 6 and IL- $1 \beta$ in a concentration-dependent manner. At a concentration of $1 \mu \mathrm{M}$, these compounds restored pro-inflammatory gene expression to non-stimulated levels; at higher concentrations, they produced even more dramatic effects, reducing IL- 6 and IL-1 $\beta$ expression to levels lower than those in unstimulated control cells. Interestingly, similar results were obtained for $\mathrm{TNF} \alpha$ expression. TNF $\alpha$ is a major pro-inflammatory cytokine, primarily secreted by macrophages and dendritic cells, whose production is regulated, amongt others, by the NF- $\kappa$ B pathway. We demonstrated that MCL effectively inhibited the expression of TNF $\alpha$ by RAW 264.7 cells, as assessed by qRTPCR (Figure 3c), and its accumulation in the cell culture supernatant, as investigated by ELISAs (Figure 3d). As shown in Figure 3d, LPS stimulation induced almost 10-fold increase in the secretion of TNF $\alpha$ into the culture supernatant. Cotreatment with either PTL or MCL induced a concentrationdependent decrease in LPS-induced accumulation of TNFo, reducing TNF $\alpha$ levels by 1.5 -fold at a concentration of $1 \mu \mathrm{M}$ and producing maximum inhibition at $10 \mu \mathrm{M}$. Collectively, these data demonstrate that MCL display strong antiinflammatory effects as PTL, in a macrophage cell line.

\section{Inhibits LPS-Induced NF- $\kappa$ B Activation}

In order to determine whether MCL directly inhibit the NF- $\kappa$ B pathway, RAW 264.7 cells were cotransfected with the luciferase reporter construct, pNF- $\kappa \mathrm{B}-\mathrm{RE}-\mathrm{LUC}$, containing a NF- $\kappa$ B-responsive element upstream of a luciferase reporter gene, together with a CMV Renilla luciferase plasmid, control for transfection efficiency. Cells were then treated with LPS in the presence of PTL or MCL $(1-5 \mu \mathrm{M})$. LPS stimulation induced a 1.5 -fold increase in NF- $\kappa \mathrm{B}$-dependent luciferase
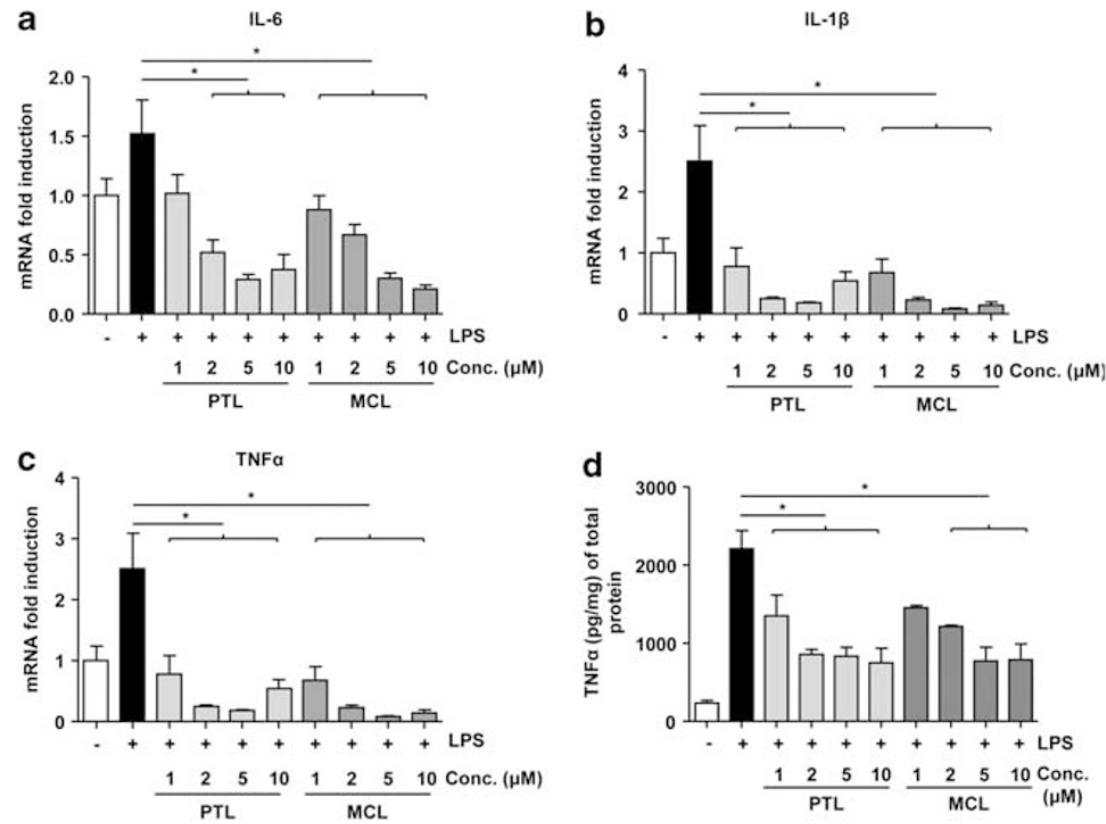

Figure 3 PTL and MCL inhibit LPS-induced cytokine secretion by macrophages in a concentration-dependent manner. (a-c) RAW 264.7 cells were treated with $0,1,2,5$, or $10 \mu \mathrm{M}$ PTL or MCL for $8 \mathrm{~h}$ and then stimulated with LPS (10 ng/ml). Total RNA was extracted and purified, and the expression of IL-1 $\beta$ (a), IL-6 (b), and TNF $\alpha$ (c) were quantified by qRT-PCR. (d) RAW 264.7 cells were stimulated with LPS (10 $\mathrm{ng} / \mathrm{ml})$ for $1 \mathrm{~h}$ and then treated with 0 , $1,2,5$, or $10 \mu \mathrm{M}$ PTL or MCL for $8 \mathrm{~h}$. TNF $\alpha$ secreted into the supernatant was assayed by ELISA. ${ }^{*} P<0.05$ compared with cells stimulated with LPS-only. 
a

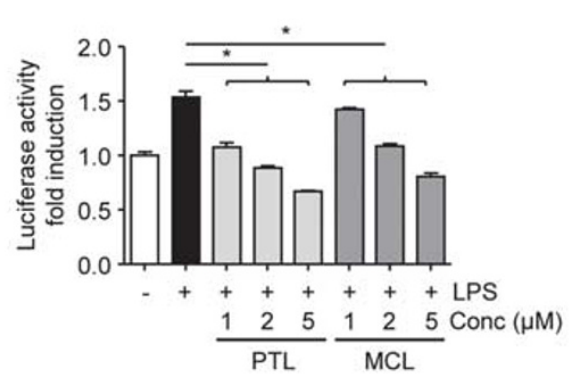

c

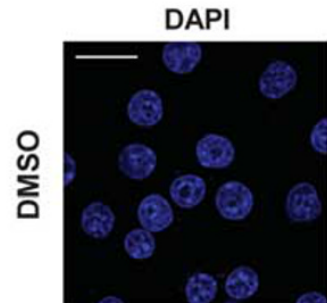

|
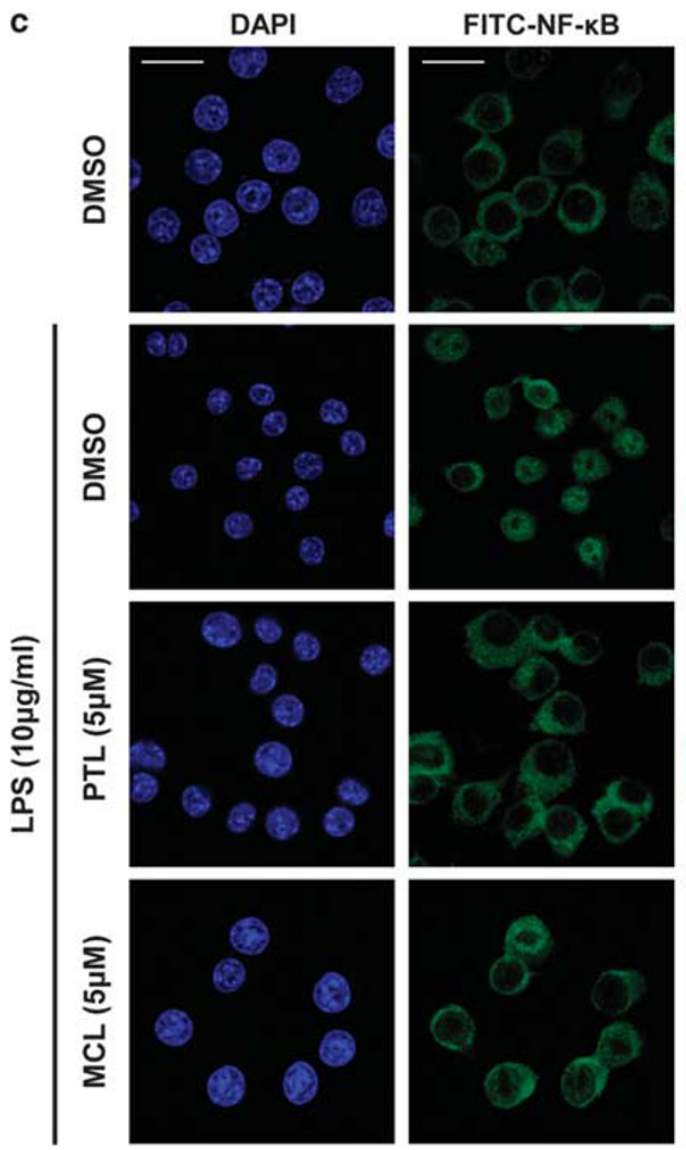

b
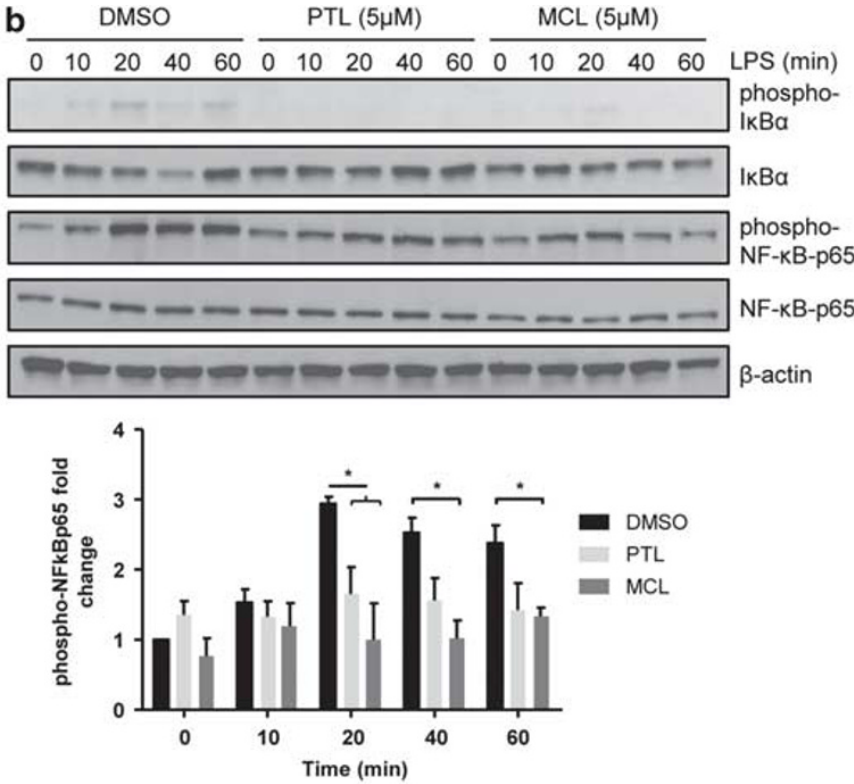

d
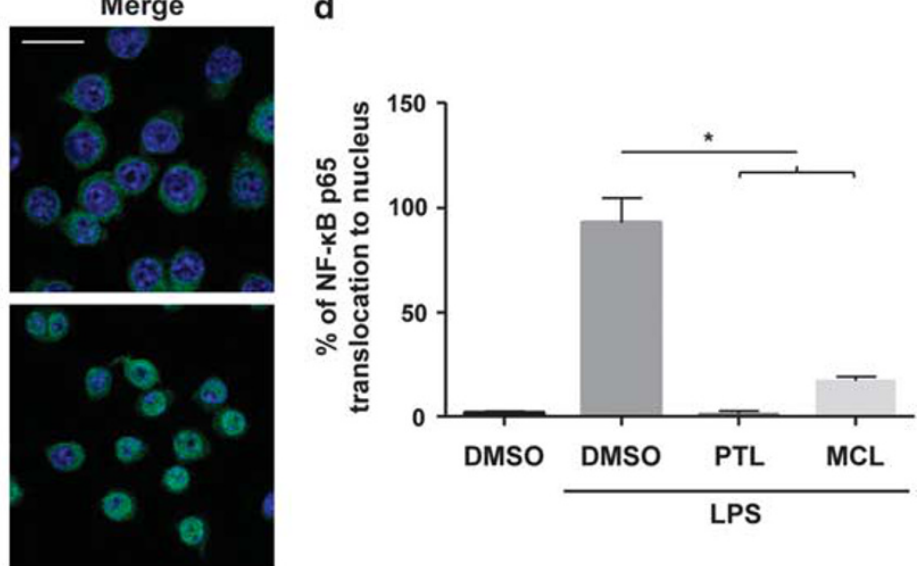
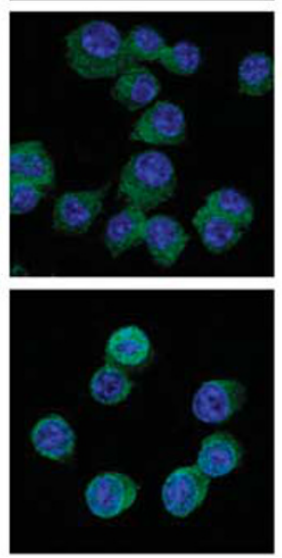

Figure 4 PTL and MCL inhibit the NF- $\kappa$ B pathway. (a) RAW 264.7 cells were transfected with the luciferase reporter construct, pNF- $\kappa$ B-RE-LUC, and treated with LPS $(100 \mathrm{ng} / \mathrm{ml})$ in combination with $0,1,2$, or $5 \mu \mathrm{M}$ PTL or MCL. Cells were lysed and luciferase activity was assessed. $* P<0.01$ compared with cells stimulated with LPS-only. (b) RAW 264.7 cells were treated with $5 \mu \mathrm{M}$ PTL or MCL for $8 \mathrm{~h}$ and then stimulated for $0,10,20,40$, or 60 min with $10 \mu \mathrm{g} / \mathrm{ml}$ of LPS. Activation of the NF- $\kappa \mathrm{B}$ pathway was analyzed by quantifying total and phosphorylated NF- $\kappa \mathrm{B}$ and total and phosphorylated $\mathrm{I} \kappa \mathrm{B} \alpha$ proteins using western blotting. Bar graph represents densitometric quantifications of phosphorylated-NF $\kappa \mathrm{B} \alpha$ western blot normalized to $\beta$-actin. Values represent means \pm s.e.m. of three blots from independent experiments. (c) The translocation of NF- $\kappa \mathrm{B}-\mathrm{p} 65$ to the nucleus was assessed by immunofluorescence. RAW 264.7 were incubated for $8 \mathrm{~h}$ with $5 \mu \mathrm{M}$ of PTL, MCL, or the DMSO control and then induced by $10 \mu \mathrm{g} / \mathrm{ml}$ of LPS for $30 \mathrm{~min}$. RAW 264.7 were immunostained using anti-NF- $\kappa$ B-p65 and cell nuclei were stained using DAPI, scale bars $=20 \mu \mathrm{m}$. (d), The percentage of NF- $\kappa$ B-p65 translocation to the nuclei was determined. 
reporter activity, indicative of LPS-induced NF- $\kappa \mathrm{B}$ activation. As shown in Figure 4a, both PTL and MCL inhibited LPS-induced NF- $\kappa \mathrm{B}$-dependent luciferase expression in a concentration-dependent manner. In order to confirm the inhibition of the NF- $\kappa$ B pathway by PTL and MCL, we examined whether these compounds interfered with activation of NF- $\kappa$ B pathway actors in RAW 264.7 cells. Cells were pretreated with $5 \mu \mathrm{M}$ PTL or MCL for $8 \mathrm{~h}$ and then stimulated with LPS for 0 to $60 \mathrm{~min}$. Accumulation of total and phosphorylated forms of the NF- $\kappa \mathrm{B}$ complex component p65 (NF- $\kappa \mathrm{B}-\mathrm{p} 65)$ as well as levels of the NF- $\kappa \mathrm{B}$ inhibitor $\mathrm{I} \kappa \mathrm{B}$, both phosphorylated and total, was investigated by western blot. Upon activation, NF- $\kappa \mathrm{B}-\mathrm{p} 65$ is phosphorylated and migrates to the nucleus, where it stimulates the transcription of target genes. Activation of the NF- $\kappa \mathrm{B}$ pathway goes through proteasome-dependent degradation of the phosphorylated form of the NF- $\kappa \mathrm{B}$ inhibitor, I $\kappa \mathrm{B}$. As shown in Figure $4 \mathrm{~b}$ and Supplementary Figure S1, LPS-induced phosphorylation of $\mathrm{I} \kappa \mathrm{B}$ was detectable within $10 \mathrm{~min}$ of stimulation. This phosphorylation resulted in the degradation of $\mathrm{I} \kappa \mathrm{B}$, as evidenced by the decreased accumulation of total I $\kappa \mathrm{B}$ observed at $40 \mathrm{~min}$ of LPS treatment. In parallel, the accumulation of the phosphorylated form of NF- $\kappa \mathrm{B}-\mathrm{p} 65$ was increased after 20 min of LPS activation, without any change in total NF- $\kappa$ B-p65. Notably, the treatment of cells with PTL and MCL reduced the LPS-dependent I $\kappa \mathrm{B}$ phosphorylation and degradation, respectively, from 60 and $10 \mathrm{~min}$ post stimulation (Supplementary Figure S1). Likewise, PTL and MCL reduced the LPS-induced NF $\kappa \mathrm{B}-\mathrm{p} 65$ phosphorylation 20 min post stimulation, with a more durable effect observed for MCL molecule (Figure $4 \mathrm{~b}$ ). Translocation of NF- $\kappa$ B-p65 to the nucleus was observed by immunofluorescence (Figure 4c). Upon LPS activation, the p65 complex migrated to the nucleus with a percentage of translocation of $93 \%$ (Figure 4c and d). Treatment with PTL and MCL, respectively, totally $(1.3 \%)$ and partially (17\%) inhibited the translocation of the p65 unit to the nucleus. Thus, activation of the NF- $\kappa$ B pathway by LPS was inhibited by PTL and MCL, as demonstrated by measuring changes in the expression of pro-inflammatory cytokines, NF- $\kappa \mathrm{B}$-p65-dependent luciferase activity, level/phosphorylation status of NF- $\kappa \mathrm{B}$ pathway actors and translocation of p65 to the nucleus.

\section{DMAMCL Ameliorates Colitis Symptoms in a Mouse Model of DSS-Induced Colitis}

To test the physiological relevance of MCL-induced inhibition of NF- $\kappa \mathrm{B}$ activation in vivo, we used a DSS-induced murine model of colitis. The pro-drugs, DMAPT and DMAMCL, display longer half-lives than the respective active drugs, PTL and MCL, and are progressively released in vivo in mouse plasma. ${ }^{20}$ We thus used DMAPT and DMAMCL for all subsequent in vivo studies. The pro-drugs DMAPT and DMAMCL were administered daily by IP at a dose of $5 \mu \mathrm{g} / \mathrm{g}$ of body weight for 5 days prior to initiating DSS treatment. After this pre-treatment, mice were simultaneously given DSS and DMAPT or DMAMCL treatment, diluted to $1.5 \%$ in drinking water, in addition to DMAPT and DMAMCL. As shown in Figure 5, administration of DSS induced classic colitis symptoms, including increased spleen weight (Figure 5a) and decreased colon length (Figure 5b). DMAPT and DMAMCL treatment significantly reduced the severity of DSS-induced colitis, as reflected in reduced spleen weight (Figure 5a) and colon length (Figure 5b). Indeed, spleen weights and colon lengths in DSS-treated mice co-treated with DMAPT or DMAMCL were comparable to those of the water-only control group.

Colon sections in mice from the water-only control group showed an intact epithelium, well-defined crypt length, no neutrophil-infiltrated edema in mucosa or submucosa, and no sign of erosions (Figure 5c). In contrast, colon tissue from DSS-treated mice showed severe inflammatory lesions throughout the mucosa, infiltration of immune cells, including neutrophils, and lymphocytes, in the lamina propria (arrows) and crypt erosion (arrowheads) (Figure 5c). Histological scoring revealed that the severity of colitis was lessened in DMAPT- and DMAMCL-treated group compared with the DSS-alone group, exhibiting minimal lymphocyte infiltration and a few, small areas of erosion (Figure $5 \mathrm{c}$ and $\mathrm{d}$ ).

Neutrophil recruitment was assessed by measuring MPO activity in the distal colon. As shown in Figure 5e, MPO activity levels were highly increased in mice with DSSinduced colitis and were significantly reduced in mice co-treated with DMAPT or DMAMCL, which reduced MPO activity levels by 1.8- and 2.1-fold, respectively, compared with the DSS-only group.

Pro-inflammatory mediators have central roles in the pathogenesis of IBD. Enhanced intestinal permeability and consequent immune cell infiltration are thought to increase mucosal production of pro-inflammatory cytokines, both by epithelial and immune cells. Using ELISA, we measured the levels of IL-6 (synthetized in response to classical NF- $\kappa$ B pathway activation) in serum (Figure 6a) and secretion of IL-1 $\beta$ (synthetized through activation of the inflammasome and cleavage of pro-IL- $1 \beta$ to mature IL- $1 \beta$ ) by the colonic mucosa (Figure 6b). DSS considerably increased the level of IL- 6 in serum and in the colonic mucosa, as measured by ELISA (Figure 6a) and qRT-PCR (Figure 6c), respectively. It also induced a substantial increase in IL1- $\beta$ in the colonic mucosa, as measured by ELISA (Figure 6b) and by qRT-PCR (Figure 6d). Treatment with DMAPT or DMAMCL significantly reduced DSS-induced secretion of these pro-inflammatory cytokines (Figure 6a-d). Importantly, TNF $\alpha$ expression in the colon, assessed by qRTPCR (Figure 6e), was decreased in the DMAPT- and DMAMCL-treatment groups compared with the DSS-only group. Taken together, these results show that both DMAPT and DMAMCL exert efficient anti-inflammatory effects in vivo and are able to inhibit experimentally induced intestinal inflammation. 

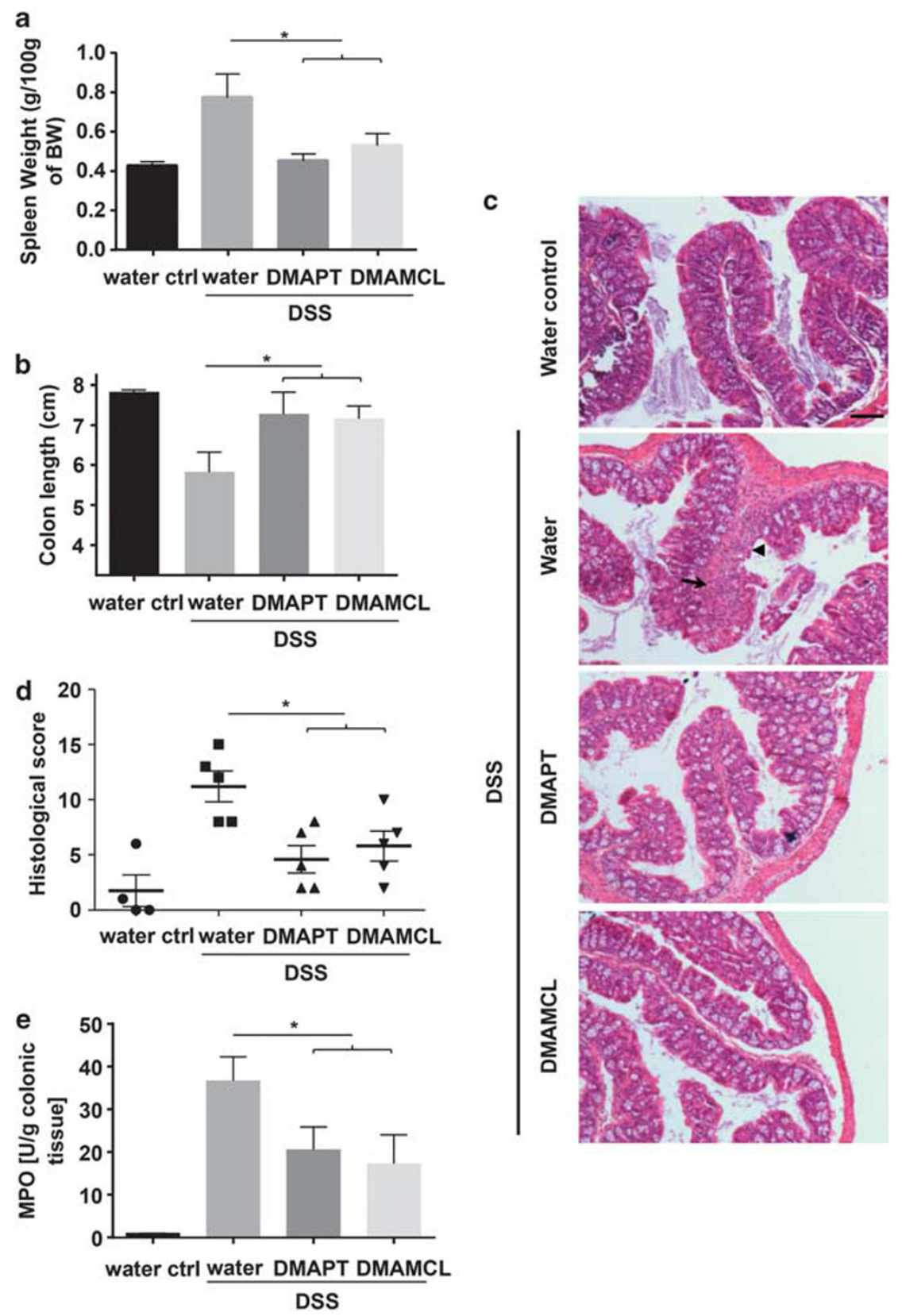

Figure 5 DMAPT and DMAMCL decrease colitis severity in a DSS-induced colitis model. WT mice were subjected to 5 days of DMAPT or DMAMCL pretreatment followed by 7 days of simultaneous addition of DMAPT and DMAMCL and DSS. Spleen weights (a) and colon lengths (b) were measured. ${ }^{*} P<0.05$ compared with mice treated with DSS only. (c) Representative H\&E-stained colons. Scale bar $=100 \mu \mathrm{m}$. (d) Histological scores determined from H\&E-stained colons. (e) Colonic MPO activity was quantified in the distal colon. ${ }^{*} P<0.05$ compared with mice treated with DSS only.

Orally Administered DMAPT and DMAMCL in Hydrogel, Efficiently Attenuate DSS-Induced Colitis

The biological properties of polysaccharides have been exploited for decades for their use in applications, such as wound healing, cell encapsulation, or as oral delivery vehicles. ${ }^{33,34}$ We used a polysaccharide gel containing two polymers, alginate and chitosan, as a delivery vector for DMAPT and DMAMCL. ${ }^{35}$ Chitosan is a biocompatible and biodegradable polymer. ${ }^{36,37}$ Alginate and chitosan form gels that chelate with calcium or sulfate in solution, respectively. ${ }^{38}$ The combination of alginate and chitosan chelation maintains the three-dimensional shape of the scaffold. Chitosan also has therapeutic effects on inflammatory cells. 38,39 Notably, chitosan oligosaccharides have a stimulatory effect on macrophages and are chemoattractants for neutrophils both in vitro and in vivo; this neutrophil infiltration being an 

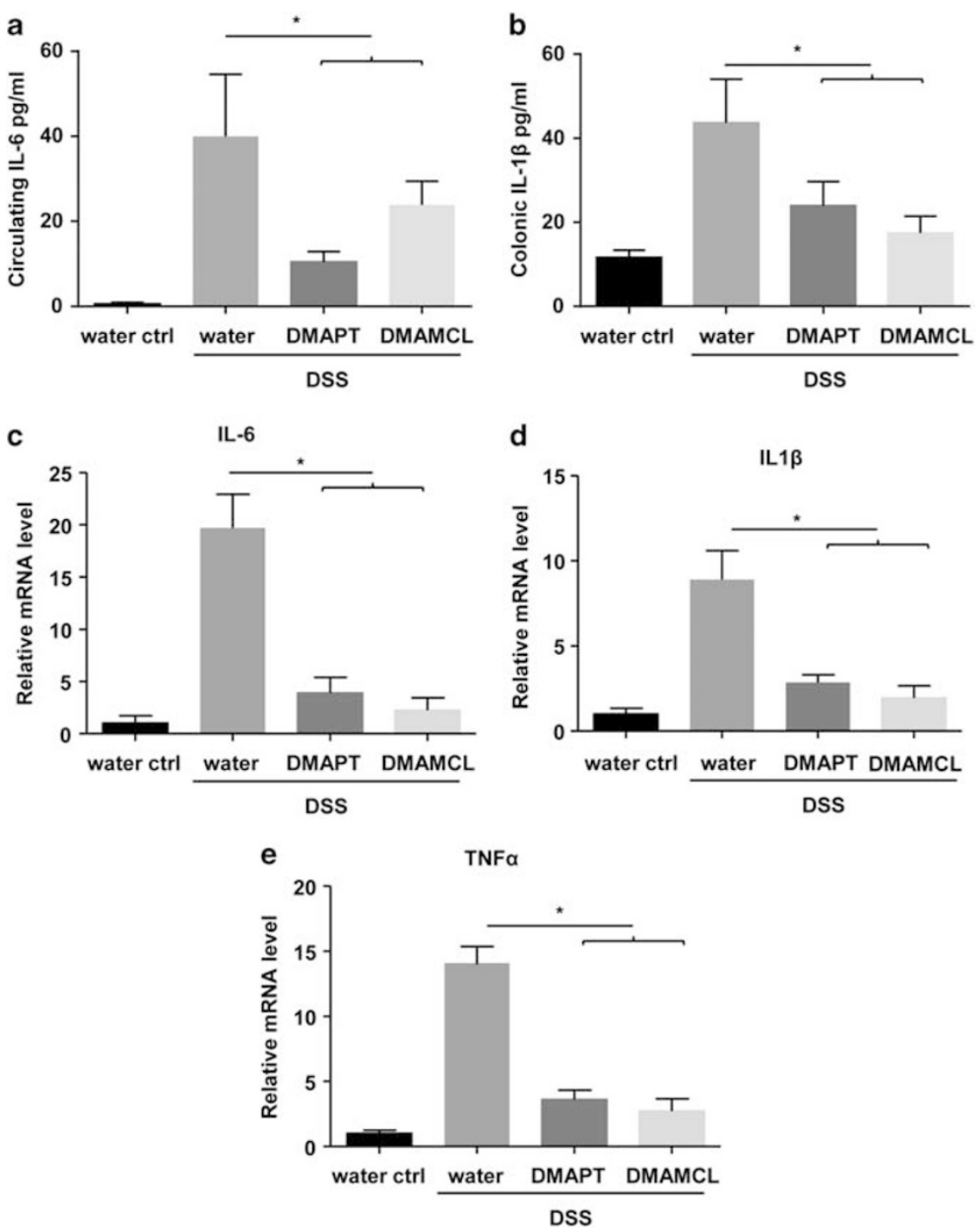

Figure 6 DMAPT and DMAMCL inhibit the expression of DSS-induced pro-inflammatory markers. (a and $\mathbf{b})$ IL-6 was quantified in serum (a), and IL-1 $\beta$ was quantified in the colonic supernatant (b). (c-e) Colonic mRNA levels of IL-6 (c) IL1- $\beta$ (d) and TNF $\alpha$ (e) were quantified by qRT-PCR and normalized to mRNA levels for the ribosomal protein 36B4. ${ }^{*} P<0.05$ compared with mice treated with DSS only.

early event essential for accelerated wound healing. ${ }^{39}$ Thus, this property can be an additional advantage in using hydrogels to administer anti-inflammatory drugs. The microscopic structure of hydrogels was examined using scanning electronic microscopy (Supplementary Figure S2). The prodrugs DMAPT and DMAMCL were administrated by double gavage (alginate/chitosan hydrogel containing the drugs followed by a calcium solution) at a concentration of $40 \mu \mathrm{g} / \mathrm{g}$ of body weight daily for 5 days before DSS treatment. After this pre-treatment, mice were co-treated with DSS (diluted to $1.5 \%$ in drinking water) and DMAPT, DMAMCL, or hydrogel alone. DSS-induced experimental colitis was assessed by measuring spleen weight and colon length. As expected, administration of DSS induced an increase in spleen weight (Figure 7a) and a decrease in colon length (Figure 7b), albeit to a lesser extent than previously observed (Figure 5), probably reflecting a decrease in water consumption owing to the water brought in with hydrogel treatment. Co-treatment of DSS-treated mice with DMAPT or DMAMCL normalized spleen weights and restored colon lengths to a size comparable to that in the water-only control group. Histological analyses and scoring revealed that the severity of colitis was greatly attenuated in DMAPT- and DMAMCL-treated groups compared with the DSS-only group, showing minimal lymphocyte infiltration and an absence of crypt erosion (Figure $7 \mathrm{c}$ and d). As shown in Figure 7e, MPO activity levels were increased in mice with DSS-induced colitis and were significantly lowered in mice treated with DMAPT or DMAMCL. qRT-PCR analyses of the expression levels of pro-inflammatory cytokines encoding genes revealed that 

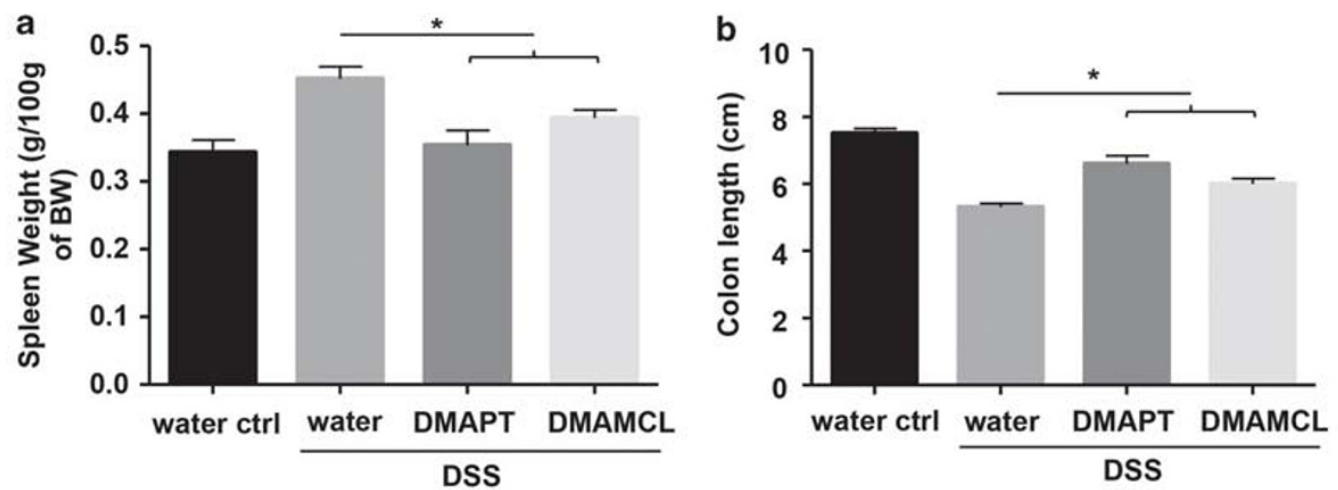

C

DSS
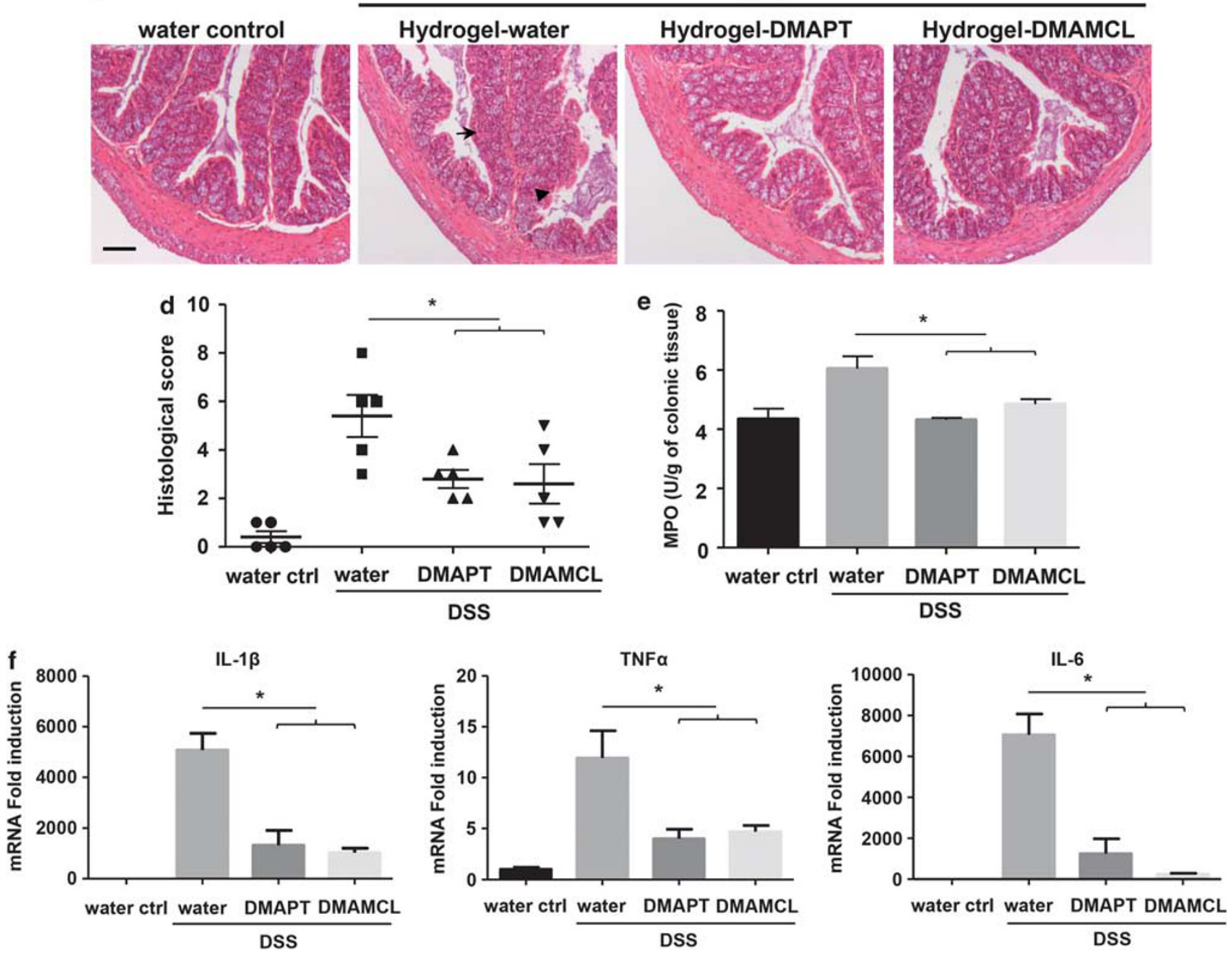

Figure 7 Oral administration of hydrogel-encapsulated DMAPT or DMAMCL inhibits DSS-induced colitis. WT mice were orally administered hydrogelencapsulated DMAPT or DMAMCL daily for 5 days followed by 7 days of DSS treatment. Spleen weights (a) and colon lengths (b) were measured. (c) Representative H\&E-stained colons. Scale bar $=100 \mu \mathrm{m}$. (d) Histological scores determined from H\&E-stained colons. (e) Colonic MPO activity was quantified in the distal colon. (f) Colonic mRNA levels of IL1- $\beta$, TNF $\alpha$, and IL- 6 were quantified by qRT-PCR and normalized to mRNA levels for the ribosomal protein $36 \mathrm{~B} 4$. ${ }^{*} P<0.05$ compared with mice treated with DSS only.

DSS-induced IL-1 $\beta, \mathrm{TNF} \alpha$ and IL-6 expression were profoundly reduced by co-treatment with DMAPT or DMAMCL.
Collectively, these data demonstrate that orally administered DMAPT or DMAMCL encapsulated in hydrogels efficiently minimize DSS-induced colitis. These results show that 
the beneficial effects of both DMAPT and DMAMCL were maintained with oral administration in a hydrogel, suggesting the potential therapeutic use of these two drugs in human therapy for IBD.

\section{DMAMCL is More Efficient than DMAPT in Reducing CAC Development in Mice}

The important inhibitory effects of DMAPT and DMAMCL on activation of pro-inflammatory pathways, as revealed using the DSS-induced model of colitis, prompted us to investigate the impact of these two compounds on inflammation-associated tumorigenesis using a mouse model of CAC. WT mice were IP injected with the procarcinogen AOM followed by two cycles of $2.5 \%$ DSS administration. The prodrug DMAPT and DMAMCL were IP-administrated daily at a concentration of $10 \mu \mathrm{g} / \mathrm{g}$ of body weight for 5 days before the start of the AOM/DSS protocol, and on a daily basis in parallel with the AOM/DSS protocol.

Consistent with previous studies using this model, ${ }^{30} \mathrm{AOM} /$ DSS-treated mice developed tumors in the middle to distal portion of the colon (Figure 8a). DMAMCL treatment significantly and consistently decreased the number of tumors per mouse (Figure $8 \mathrm{a}$ and $\mathrm{b}$ ) and reduced average tumor size and total tumor area compared with treatment with AOM/ DSS alone (Figure $8 \mathrm{c}$ and $\mathrm{d}$ ). Treatment with DMAPT produced a similar trend towards decreased numbers of tumors per mouse, tumor size, and total tumor area, although these differences failed to reach statistical significance owing to substantial inter-individual variability (Figure 8a-d). DMAPT and DMAMCL also showed a trend toward attenuating the weight loss associated with AOM/DSS treatment, an effect that also fell short of statistical significance (Supplementary Figure S3).

Histological examinations consistently showed large adenomas with major inflammatory cell infiltration in colonic sections from AOM/DSS-treated mice (Figure 8e). The size of the adenomas and the area of the inflammatory cell infiltration were decreased in both DMAPT- and DMAMCLtreated groups compared with the AOM/DSS-only group. Colonic MPO activity was increased in the AOM/DSStreated group compared with that in the water-only control group (Figure 8f). Importantly, DMAPT and DMAMCL treatment significantly reduced AOM/DSS-induced MPO activity.

In addition, expression of genes encoding the pro-inflammatory cytokines IL- $1 \beta$, TNF $\alpha$, and IL- 6 , which can increase owing to the tumor development but can also promote their growth, ${ }^{5}$ was highly induced in the AOM/DSS-treated group compared with the water-only control group (Figure 9a). Treatment with DMAPT or DMAMCL significantly decreased the expression of IL- $1 \beta, \mathrm{TNF} \alpha$, and IL- 6 encoding genes. Importantly, DMAMCL strongly inhibited IL-6 expression, reducing its expression nearly to water-only control group levels. We therefore examined the effects of DMAPT and DMAMCL on the proliferation markers cyclin D1 and PCNA (proliferating cell nuclear antigen). As shown in Figure 9b, AOM/DSS-induced accumulation of cyclin D1 and PCNA was inhibited by treatment with DMAPT or DMAMCL. Interestingly, the inhibitory effects of DMAMCL on both cyclin D1 and PCNA were greater than those of DMAPT. In order to demonstrate that daily administration of DMAPT or DMAMCL did not deleteriously affect the intestinal barrier or cause organ damage, we IP injected WT mice daily with water, DMAPT, or DMAMCL for 47 days. Intestinal barrier function was analyzed using a FITC-labeled dextran method, as described in Materials and Methods. Mice were administered FITC-dextran by gavage, and fluorescence was quantified in the serum $5 \mathrm{~h}$ later. As shown in Supplementary Figure S4, the Dextran-FITC concentration in serum was decreased in mice in the DMAPT and DMAMCL group compared with those in the water control group, suggesting that DMAPT or DMAMCL treatment effectively decreases intestinal permeability. In addition, spleen weight, colon length, and colon weight were unaffected by daily IP injection of DMAPT or DMAMCL (Supplementary Figure S5A). Histology examination of the H\&E-stained colon, liver, spleen, and kidney showed no morphological differences between water-, DMAPT-, or DMAMCL-treated groups (Supplementary Figure S5B). Taken together, these data indicate that DMAPT and DMAMCL improve intestinal barrier function without causing any deleterious effects, and support the conclusion that both DMAMCL and DMAPT, but especially DMAMCL, reduce CAC development in mice.

\section{DISCUSSION}

In the present study, we compared the anti-inflammatory and NF- $\kappa \mathrm{B}$ pathway-inhibitory effects of MCL and PTL in vitro, and found that MCL, like PTL, inhibited the LPS-induced inflammatory response, which is linked to strong NF- $\kappa \mathrm{B}$ activation. We investigated the effect of IP injection of DMAPT or DMAMCL in a murine model of DSS-induced colitis, and showed that both DMAPT and DMAMCL attenuated this chemically induced colitis. As it is known that chronic colonic inflammation can lead to CAC, we investigated DMAMCL and DMAPT effects in an AOM/DSS model of CAC, and observed that DMAMCL more effectively attenuated tumor lesions than did DMAPT. We next investigated the efficacy of orally administered DMAPT and DMAMCL encapsulated in hydrogel, and demonstrated that hydrogelencapsulated DMAPT and DMAMCL attenuated colitis in the DSS-mouse model. Taken together, these data provide experimental evidence that both DMAPT and DMAMCL possess strong anti-inflammatory properties when orally administrated and could be envisaged as therapeutic agents for patients with IBD or CAC.

Based on in vitro test, we demonstrated that the molecular mechanism of action of MCL is similar to that of PTL, and beneficial effects are attributable to inhibition of NF- $\kappa \mathrm{B}$ pathway activation and downregulation of major inflammatory mediator expression such as TNF $\alpha$ and IL-1 $\beta$. Our 

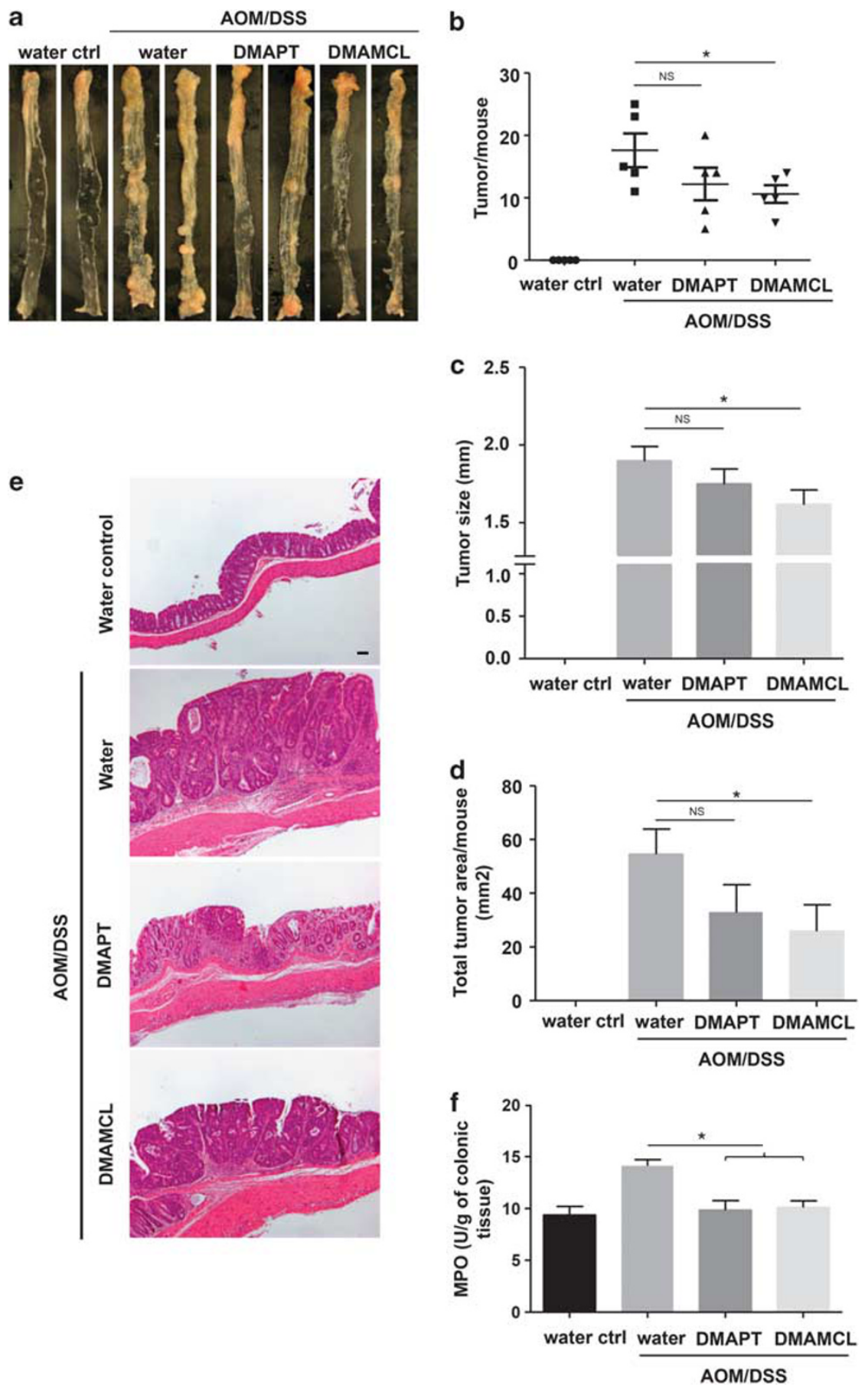

Figure 8 DMAPT and DMAMCL reduce colonic tumorigenesis in a mouse model of CAC. Mice were IP injected with AOM (10 mg/kg body weight) and maintained for 7 days, then subjected to two-cycle DSS treatment (7 days of $2.5 \%$ DSS and 14 days of $\mathrm{H}_{2} \mathrm{O}$ ). (a) Representative colons obtained at the end of the CAC protocol. (b) Number of tumors per mouse. (c and d) Tumor size (c) was determined using a dissecting microscope, and total tumor area per mouse (d) was calculated. (e) Representative H\&E-stained colonic tumors at the end of the CAC protocol. Scale bars $=100 \mu \mathrm{m}$. (f) Colonic MPO activity was quantified in the distal colon. ${ }^{*} P<0.05$ compared with mice treated with AOM/DSS only.

in vitro results attest the efficiency of PTL and MCL as NF- $\kappa \mathrm{B}$ inhibitors, particularly with respect to the main downstream actor in the NF- $\kappa \mathrm{B}$ pathway, $\mathrm{TNF} \alpha$, showing that both of these compounds very efficiently inhibited its secretion.
We also demonstrated a drastic inhibitory effect of DMAPT and DMAMCL on TNF $\alpha$ expression in vivo using two different mouse models (DSS and AOM/DSS) and two routes of administration (IP and oral). 
a

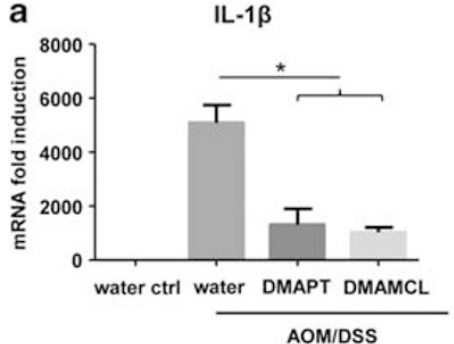

b

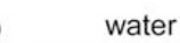

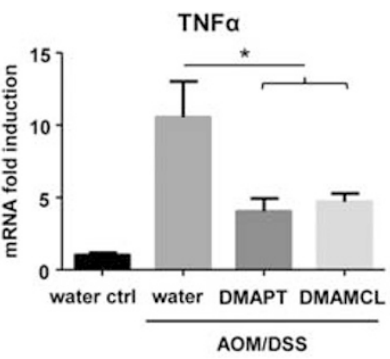

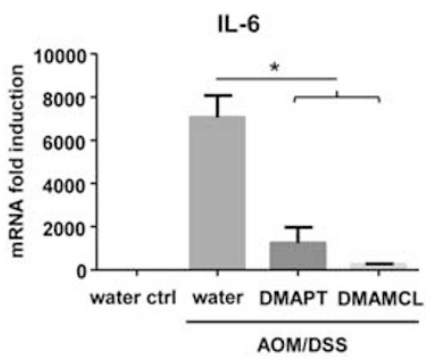

AOM/DSS
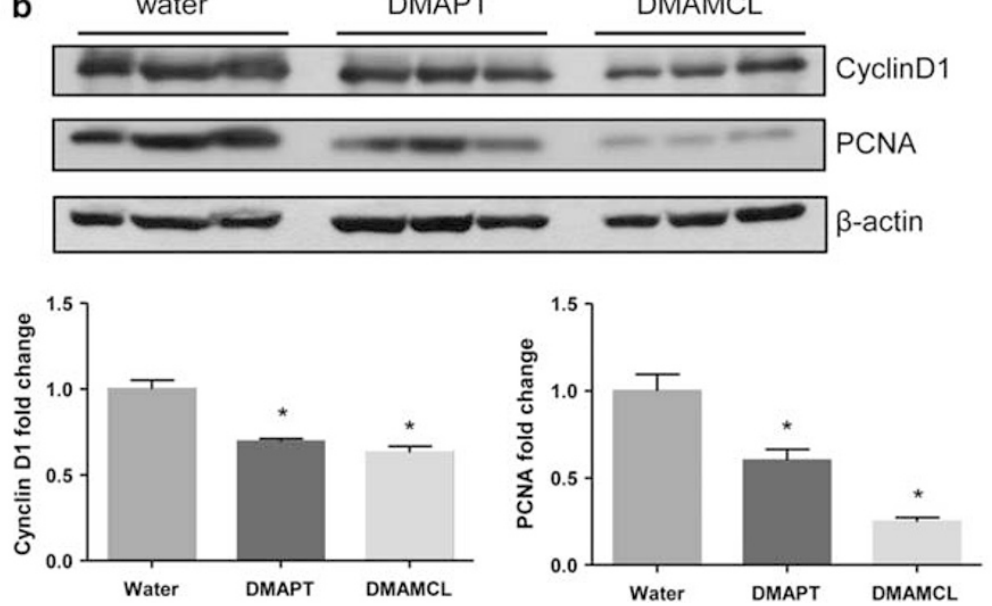

Figure 9 DMAPT and DMAMCL inhibit the AOM/DSS-induced increase in pro-inflammatory markers. (a) Colonic mRNA levels of IL-1 $\beta$, TNF $\alpha$, and IL-6 were quantified by qRT-PCR and normalized to mRNA levels for the ribosomal protein 36B4. ${ }^{*} P<0.05$ compared with mice treated with AOM/DSS only. (b) Cyclin D1, PCNA, and $\beta$-actin proteins in mice treated with AOM/DSS and DMAPT, DMAMCL, or water only (control) were analyzed by western blotting. Bar graph represents the densitometric quantification of Cyclin D1 and PCNA normalized to $\beta$-actin. ${ }^{*} P<0.05$ compared with mice treated with AOM/DSS only.

$\mathrm{TNF} \alpha$ is known to have a pivotal role in the pathogenesis of IBD. ${ }^{40}$ When released by active macrophages and $\mathrm{T}$ lymphocytes, TNF $\alpha$ initiates multiple biological processes, modulating immune cell function, driving adaptive immune responses, triggering epithelial cell apoptosis, disrupting the epithelial barrier, and inducing endothelial expression of adhesion molecules. Clinical studies have shown that TNF $\alpha$ protein and mRNA levels are elevated in serum, intestinal tissue and stools of patients with active IBD, and correlate with disease activity. ${ }^{40-43}$ Clinical inhibition of TNF $\alpha$ activity has been linked to disease remission, improved life quality and relapse prevention; conversely, failure of clinical treatment of IBD has been attributed to early reactivation of TNF $\alpha$-secretory capacity by immune cells. ${ }^{44,45}$ Thus, TNF $\alpha$ activity is critical for disease development, and inhibiting TNF $\alpha$ production in inflamed mucosa is one of the main goals in IBD management. Neutralization of TNF $\alpha$ by monoclonal antibodies has been shown to be an effective approach for treating IBD. One such monoclonal anti-TNF $\alpha$ antibody, Infliximab, has been used to treat IBD since $1998 .{ }^{45}$ However, Infliximab must be administered systemically and its use is limited owing to serious side effects, including acute or delayed infusion reactions, leukopenia, serious infection, antichimeric antibody formation, increased risk of malignancy and lymphoma as well as psoriasis. ${ }^{46-53}$ Thus, there is an unmet need for a carrier system capable of specifically and exclusively delivering drugs to the inflamed regions for a prolonged period of time. Such a system could significantly reduce side effects of existing, otherwise effective, treatments. The strong TNF $\alpha$-inhibitory effect of orally delivered DMAPT and DMAMCL suggests that these compounds could be alternatives and/or complement approach to Infliximab. PTL has a long history of medicinal use from ancient times to the present in a number of countries and is known to possess a variety of beneficial pharmacological properties, including anti-inflammatory, antitumor, and anti-infectious activities. Numerous clinical trials as well as animal studies have shown that PTL treatment is associated with only few toxic or side effects. Moreover, the PTL derivate, MCL is not cytotoxic in vivo. ${ }^{20}$ It is therefore reasonable to expect that PTL and MCL might be safe and useful therapeutic drugs for the treatment of IBD.

It is widely recognized that inflammation can contribute to tumor formation and growth; ${ }^{8,9}$ the strongest example of this association is colon carcinogenesis arising in IBD patients. ${ }^{7}$ This study provides the first demonstration of the beneficial 
effects of DMAPT and DMAML on CAC, and further shows that amelioration of CAC is more striking and consistent with DMAMCL, the pro-drug for MCL. It is then reasonable to expect that MCL could move forward to clinical trials, where it could ultimately prove to be a useful therapeutic agent for the treatment of IBD as well as subsequent CAC.

Supplementary Information accompanies the paper on the Laboratory Investigation website (http://www.laboratoryinvestigation.org)

\section{ACKNOWLEDGMENTS}

This work was supported by grants from the Department of Veterans Affairs (BX002526-01) and the National Institutes of Health of Diabetes and Digestive and Kidney by the grant RO1-DK-071594 and 5R01DK064711 (to DM), the American Heart Association Postdoctoral Fellowship Grant 13POST16400004 (to BX) and the National Natural Science Foundation of China (NSFC) NO. 21372129 (to YC). D Merlin is a recipient of a VA research Career Scientist Award. EV and DM conceived and designed the experiments, analyzed the data, and wrote the manuscript. EV performed the experiments. BX, LW, and SA contributed reagents and materials. PGW, QZ and YC synthesized and provided the drugs PTL, MCL, DMAPT, and DMAMCL. All the authors participated in general discussions, read, commented, and approved of the final the manuscript.

\section{DISCLOSURE/CONFLICT OF INTEREST}

$Y C$ is one of the founders of Accendatech Co., Ltd., which has a financial interest in DMAMCL. All other authors declare no conflict of interest.

1. Loftus Jr EV. Clinical epidemiology of inflammatory bowel disease: Incidence, prevalence, and environmental influences. Gastroenterology 2004;126:1504-1517.

2. Saleh M, Elson CO. Experimental inflammatory bowel disease: insights into the host-microbiota dialog. Immunity 2011;34:293-302.

3. Khor B, Gardet A, Xavier RJ. Genetics and pathogenesis of inflammatory bowel disease. Nature 2011;474:307-317.

4. Sakata K, Yamashita T, Maeda M, et al. Cloning of a lymphatic peptide/ histidine transporter. Biochem J 2001;356(Pt 1):53-60.

5. Terzic J, Grivennikov S, Karin E, et al. Inflammation and colon cancer. Gastroenterology 2010;138:2101-2114 e2105.

6. Jemal A, Bray F, Center MM, et al. Global cancer statistics. CA Cancer J Clin 2011;61:69-90.

7. Coussens LM, Werb Z. Inflammation and cancer. Nature 2002;420: 860-867.

8. Karin $M$, Lawrence $T$, Nizet $V$. Innate immunity gone awry: linking microbial infections to chronic inflammation and cancer. Cell 2006;124:823-835.

9. Viennois E, Chen F, Merlin D. NF-kappaB pathway in colitis-associated cancers. Transl Gastrointest Cancer 2013;2:21-29.

10. Heinrich M, Robles M, West JE, et al. Ethnopharmacology of Mexican asteraceae (Compositae). Annu Rev Pharmacol Toxicol 1998;38: 539-565.

11. Hehner SP, Heinrich M, Bork PM, et al. Sesquiterpene lactones specifically inhibit activation of NF-kappa B by preventing the degradation of I kappa B-alpha and I kappa B-beta. J Biol Chem 1998:273:1288-1297.

12. Saadane A, Masters S, DiDonato J, et al. Parthenolide inhibits IkappaB kinase, NF-kappaB activation, and inflammatory response in cystic fibrosis cells and mice. Am J Respir Cell Mol Biol 2007;36:728-736.

13. Zhao ZJ, Xiang JY, Liu L, et al. Parthenolide, an inhibitor of the nuclear factor-kappaB pathway, ameliorates dextran sulfate sodium-induced colitis in mice. Int Immunopharmacol 2012;12:169-174.

14. Kim JH, Liu L, Lee SO, et al. Susceptibility of cholangiocarcinoma cells to parthenolide-induced apoptosis. Cancer Res 2005;65:6312-6320.

15. Nakshatri H, Rice SE, Bhat-Nakshatri P. Antitumor agent parthenolide reverses resistance of breast cancer cells to tumor necrosis factorrelated apoptosis-inducing ligand through sustained activation of c-Jun N-terminal kinase. Oncogene 2004;23:7330-7344.
16. Park $\mathrm{JH}$, Liu L, Kim $\mathrm{IH}$, et al. Identification of the genes involved in enhanced fenretinide-induced apoptosis by parthenolide in human hepatoma cells. Cancer Res 2005;65:2804-2814.

17. Yip-Schneider MT, Wu H, Njoku V, et al. Effect of celecoxib and the novel anti-cancer agent, dimethylamino-parthenolide, in a developmental model of pancreatic cancer. Pancreas 2008;37:e45-e53.

18. Zhang S, Ong CN, Shen HM. Critical roles of intracellular thiols and calcium in parthenolide-induced apoptosis in human colorectal cancer cells. Cancer Lett 2004;208:143-153.

19. Neelakantan S, Nasim S, Guzman ML, et al. Aminoparthenolides as novel anti-leukemic agents: Discovery of the NF-kappaB inhibitor, DMAPT (LC-1). Bioorg Med Chem Lett 2009;19:4346-4349.

20. Zhang $Q$, Lu Y, Ding $Y$, et al. Guaianolide sesquiterpene lactones, a source to discover agents that selectively inhibit acute myelogenous leukemia stem and progenitor cells. J Med Chem 2012;55: 8757-8769.

21. Shanmugam R, Kusumanchi $P$, Cheng $L$, et al. A water-soluble parthenolide analogue suppresses in vivo prostate cancer growth by targeting NFkappaB and generating reactive oxygen species. Prostate 2010;70:1074-1086.

22. Shanmugam R, Kusumanchi P, Appaiah $\mathrm{H}$, et al. A water soluble parthenolide analog suppresses in vivo tumor growth of two tobaccoassociated cancers, lung and bladder cancer, by targeting NF-kappaB and generating reactive oxygen species. Int J Cancer 2011;128: 2481-2494.

23. Jin P, Madieh S, Augsburger LL. The solution and solid state stability and excipient compatibility of parthenolide in feverfew. AAPS PharmSciTech 2007;8:E105.

24. Zhai JD, Li D, Long J, et al. Biomimetic semisynthesis of arglabin from parthenolide. J Org Chem 2012;77:7103-7107.

25. Ding YH, Fan HX, Long J, et al. The application of Heck reaction in the synthesis of guaianolide sesquiterpene lactones derivatives selectively inhibiting resistant acute leukemic cells. Bioorg Med Chem Lett 2013;23:6087-6092.

26. Ma WW, Shi QQ, Ding YH, et al. Synthesis of micheliolide derivatives and their activities against AML progenitor cells. Molecules 2013; 18:5980-5992.

27. Viennois $\mathrm{E}, \mathrm{Chen} \mathrm{F}$, Laroui $\mathrm{H}$, et al. Dextran sodium sulfate inhibits the activities of both polymerase and reverse transcriptase: lithium chloride purification, a rapid and efficient technique to purify RNA. BMC Res Notes 2013;6:360.

28. Charrier L, Yan Y, Driss A, et al. ADAM-15 inhibits wound healing in human intestinal epithelial cell monolayers. Am J Physiol Gastrointest Liver Physiol 2005;288:G346-G353.

29. Laroui H, Sitaraman SV, Merlin D. Gastrointestinal delivery of antiinflammatory nanoparticles. Methods Enzymol 2012;509:101-125.

30. Greten FR, Eckmann L, Greten TF, et al. IKKbeta links inflammation and tumorigenesis in a mouse model of colitis-associated cancer. Cell 2004;118:285-296.

31. Katakura K, Lee J, Rachmilewitz D, et al. Toll-like receptor 9-induced type I IFN protects mice from experimental colitis. J Clin Invest 2005;115:695-702.

32. Chassaing B, Srinivasan G, Delgado MA, et al. Fecal lipocalin 2, a sensitive and broadly dynamic non-invasive biomarker for intestinal inflammation. PLoS One 2012;7:e44328.

33. Burd DA, Greco RM, Regauer S, et al. Hyaluronan and wound healing: a new perspective. Br J Plast Surg 1991;44:579-584.

34. Clayton HA, London NJ, Colloby PS, et al. The effect of capsule composition on the biocompatibility of alginate-poly-l-lysine capsules. J Microencapsul 1991;8:221-233.

35. Laroui H, Dalmasso G, Nguyen HT, et al. Drug-loaded nanoparticles targeted to the colon with polysaccharide hydrogel reduce colitis in a mouse model. Gastroenterology 2010;138:843-853, e841-842.

36. Azab AK, Orkin B, Doviner V, et al. Crosslinked chitosan implants as potential degradable devices for brachytherapy: in vitro and in vivo analysis. J Control Release 2006;111:281-289.

37. Tozaki H, Odoriba T, Okada N, et al. Chitosan capsules for colonspecific drug delivery: enhanced localization of 5-aminosalicylic acid in the large intestine accelerates healing of TNBS-induced colitis in rats. J Control Release 2002;82:51-61.

38. Mladenovska K, Raicki RS, Janevik El, et al. Colon-specific delivery of 5-aminosalicylic acid from chitosan-Ca-alginate microparticles. Int J Pharm 2007;342:124-136. 
39. Shi C, Zhu $Y$, Ran $X$, et al. Therapeutic potential of chitosan and its derivatives in regenerative medicine. J Surg Res 2006;133: 185-192.

40. Papadakis KA, Targan SR. Role of cytokines in the pathogenesis of inflammatory bowel disease. Annu Rev Med 2000;51:289-298.

41. Komatsu M, Kobayashi D, Saito K, et al. Tumor necrosis factor-alpha in serum of patients with inflammatory bowel disease as measured by a highly sensitive immuno-PCR. Clin Chem 2001;47:1297-1301.

42. Stevens C, Walz G, Singaram C, et al. Tumor necrosis factor-alpha, interleukin-1 beta, and interleukin-6 expression in inflammatory bowe disease. Dig Dis Sci 1992;37:818-826.

43. Wang J, Fu YX. Tumor necrosis factor family members and inflammatory bowel disease. Immunol Rev 2005;204:144-155.

44. Nikolaus S, Raedler A, Kuhbacker $T$, et al. Mechanisms in failure of infliximab for Crohn's disease. Lancet 2000;356:1475-1479.

45. Rutgeerts $P$, Van Assche G, Vermeire S. Optimizing anti-TNF treatment in inflammatory bowel disease. Gastroenterology 2004;126: 1593-1610.

46. Biancone L, Petruzziello C, Orlando A, et al. Cancer in Crohn's Disease patients treated with infliximab: a long-term multicenter matched pair study. Inflamm Bowel Dis 2011;17:758-766.
47. Miele E, Markowitz JE, Mamula P, et al. Human antichimeric antibody in children and young adults with inflammatory bowel disease receiving infliximab. J Pediatr Gastroenterol Nutr 2004;38:502-508.

48. Parashette KR, Makam RC, Cuffari C. Infliximab therapy in pediatric Crohn's disease: a review. Clin Exp Gastroenterol 2010;3:57-63.

49. Schneeweiss S, Korzenik J, Solomon DH, et al. Infliximab and other immunomodulating drugs in patients with inflammatory bowe disease and the risk of serious bacterial infections. Aliment Pharmacol Ther 2009;30:253-264.

50. Sherlock ME, Bandsma R, Ota $\mathrm{K}$, et al. Severe neutropenia following infliximab treatment in a child with ulcerative colitis. Inflamm Bowel Dis 2011;17:E17-E18.

51. Steenholdt $C$, Svenson $M$, Bendtzen $K$, et al. Severe infusion reactions to infliximab: aetiology, immunogenicity and risk factors in patients with inflammatory bowel disease. Aliment Pharmacol Ther 2011;34:51-58.

52. Veereman-Wauters $G$, de Ridder $L$, Veres $G$, et al. Risk of infection and prevention in pediatric patients with IBD: ESPGHAN IBD Porto Group commentary. J Pediatr Gastroenterol Nutr 2012;54:830-837.

53. Iborra M, Beltran B, Bastida G, et al. Infliximab and adalimumabinduced psoriasis in Crohn's disease: a paradoxical side effect. J Crohns Colitis 2011;5:157-161. 